Article

\title{
Study on the Optimal Operation of a Hydropower Plant Group Based on the Stochastic Dynamic Programming with Consideration for Runoff Uncertainty
}

\author{
Hongxue Zhang ${ }^{1,+}$, Lianpeng Zhang ${ }^{2,+}$, Jianxia Chang ${ }^{2, *}$, Yunyun $\mathrm{Li}^{3}{ }^{3}$, , Ruihao Long ${ }^{4}$ and Zhenxiang Xing ${ }^{1}(\mathbb{D}$ \\ 1 School of Water Conservancy \& Civil Engineering, Northeast Agricultural University, Harbin 150030, China; \\ hongxue@neau.edu.cn (H.Z.); zxxing@neau.edu.cn (Z.X.) \\ 2 State Key Laboratory of Eco-hydraulics in Northwest Arid Region, Xi'an University of Technology, \\ Xi'an 710048, China; scsppp@163.com \\ 3 College of Resources and Environmental Engineering, Mianyang Normal University, \\ Mianyang 621000, China; liyunyun19900627@163.com \\ 4 Shaanxi Province Institute of Water Resources and Electric Power Investigation and Design, \\ Xi'an 710005, China; 1985107613@163.com \\ * Correspondence: chxiang@xaut.edu.cn \\ + These authors contributed equally to this work.
}

check for

updates

Citation: Zhang, H.; Zhang, L.;

Chang, J.; Li, Y.; Long, R.; Xing, Z. Study on the Optimal Operation of a Hydropower Plant Group Based on the Stochastic Dynamic

Programming with Consideration for Runoff Uncertainty. Water 2022, 14,

220. https://doi.org/10.3390/ w14020220

Academic Editor: Marco Franchini

Received: 14 December 2021

Accepted: 10 January 2022

Published: 12 January 2022

Publisher's Note: MDPI stays neutral with regard to jurisdictional claims in published maps and institutional affiliations.

Copyright: () 2022 by the authors Licensee MDPI, Basel, Switzerland. This article is an open access article distributed under the terms and conditions of the Creative Commons Attribution (CC BY) license (https:// creativecommons.org/licenses/by/ $4.0 /)$.

\begin{abstract}
Hydropower plant operation reorganizes the temporal and spatial distribution of water resources to promote the comprehensive utilization of water resources in the basin. However, a lot of uncertainties were brought to light concerning cascade hydropower plant operation with the introduction of the stochastic process of incoming runoff. Therefore, it is of guiding significance for the practice operation to investigate the stochastic operation of cascade hydropower plants while considering runoff uncertainty. The runoff simulation model was constructed by taking the cascade hydropower plants in the lower reaches of the Lancang River as the research object, and combining their data with the copula joint function and Gibbs method, and a Markov chain was adopted to construct the transfer matrix of runoff between adjacent months. With consideration for the uncertainty of inflow runoff, the stochastic optimal operation model of cascade hydropower plants was constructed and solved by the SDP algorithm. The results showed that $71.12 \%$ of the simulated monthly inflow of 5000 groups in the Nuozhadu hydropower plant drop into the reasonable range. Due to the insufficiency of measured runoff, there were too many 0 values in the derived transfer probability, but after the simulated runoff series were introduced, the results significantly improved. Taking the transfer probability matrix of simulated runoff as the input of the stochastic optimal operation model of the cascade hydropower plants, the operation diagram containing the future-period incoming water information was obtained, which could directly provide a reference for the optimal operation of the Nuozhadu hydropower plant. In addition, taking the incoming runoff process in a normal year as the standard, the annual mean power generation based on stochastic dynamic programming was similar to that based on dynamic programming (respectively $305.97 \times 10^{8} \mathrm{~kW} \cdot \mathrm{h}$ and $306.91 \times 10^{8} \mathrm{~kW} \cdot \mathrm{h}$ ), which proved that the operation diagram constructed in this study was reasonable.
\end{abstract}

Keywords: reservoir operation; copula function; Gibbs; SDP; Lancang River

\section{Introduction}

The optimal operation of hydropower plant groups is an issue for water conservancy and hydropower systems based on the theory of the optimal single hydropower plant operation method and comprehensively considering the water conservancy relationship between hydropower plants [1,2]. The optimal operation is to reorganize the temporal and spatial distribution of water resources according to the comprehensive utilization tasks 
assigned to the hydropower plant and based on the allocation capacity of the reservoir, achieving the target of promoting benefits and eliminating hazards [3,4]. The research on the optimal operation of hydropower plant groups has a long history. Ponnambalam et al. [5] showed that an implementation of the Karmarkar's interior-point LP algorithm with a newly developed stopping criterion could solve the optimization problems of largescale multi-reservoir operations more efficiently than the simplex method. To address the deficiency of the genetic algorithm in the application of reservoir group operation, Oliveira and Loucks [6] used an improved genetic optimization algorithm to effectively formulate the operation rules of reservoir groups. Chandramouli and Raman [7] established and solved the optimal operation model of reservoir groups by using a dynamic programming algorithm and neural network. In order to enhance the performance of evolutionary algorithms, Arunkumar and Jothiprakash [8] introduced chaos technology to generate initial population and applied it to the operation optimization of their reservoir group system.

The optimal operation of a hydropower plant means meeting the requirements of flood control and benefits on the premise of ensuring the safety of reservoir engineering facilities and the ecological environment. $[9,10]$ Generally, under the optimization objective, the hydropower plant operation adopts the historical runoff as the input and obtains the optimal operation decisions for the hydropower plant for each period through intelligent algorithm technology [11,12]. However, there is a certain gap between the determined hydropower plant operation rules and the actual dispatching results [13]. One reason for this is that the stochastic inflow is not considered. The inflow is uncertain under the influence of both anthropic and natural factors [14,15], which, in time, has a certain correlation between different periods as well. Dynamic programming (DP) algorithm [16,17] is a process of searching for the optimal decision step by step, in order, at multiple stages, but it is difficult to solve the stochastic multi-stage problems. Therefore, the stochastic dynamic programming (SDP) algorithm $[18,19]$ can be used to effectively work out operation rules for the runoff uncertainty by combining the probability theory and dynamic programming principle.

The runoff process during the process of hydropower plant operation is uncertain, which limits the traditional algorithms and determined dynamic programming, while the SDP algorithm fully takes the uncertain factors into consideration [20,21]. Little [22] applied the Markov theory to construct the SDP model of a hydropower plant. Howard [23] proposed a method coupling the Markov theory with the DP (MDP), which avoids prematurely falling into the local solutions when compared with the traditional model for the multi-year issues. Rossment [24] combined the Lagrange multiplier with DP theory to establish a chance-constrained programming model. Bras et al. [25] applied the SDP method to the Aswan Dam, and the results showed that the SDP model is effective when considering runoff prediction information. Saadat M and Asghari K [26] made an improvement of the SDP algorithm by properly adjusting the interval indices of the reservoir storage capacity, which resulted in the values of the objective function increasing by $30 \%$. Therefore, it is critical to explore the issue of operation discission-making for cascade hydropower plants under the uncertainty of the incoming runoff.

The development of large-number cascade hydropower plants in the whole basin plays a great role in promoting the economic development of the Southwest of China. In previous research, most of them were certain operation, and the input used was the observed runoff [3]. However, in this paper, the distribution of uncertain incoming runoff was constructed using the copula joint function and Gibbs sampling based on the large number of simulations of observed runoff data. Moreover, Lancang River, as a transboundary river, is located in Southwest China, and the water resources are sufficient; while on the other hand, the incoming runoff in this area is uncertain as well. Therefore, it is of great significance to investigate the region's hydropower plant group while taking the uncertainty of incoming runoff into consideration. 


\section{Study Area and Data}

The source of the Lancang River is located in the Qinghai Province (Figure 1). Flowing out of China from Mengla county of Yunnan Province, it goes through five Southeast Asian countries: Myanmar, Laos, Vietnam, Cambodia, and Thailand. The Lancang River has a total length of about $2139 \mathrm{~km}$ in China, an area of $164,800 \mathrm{~km}^{2}$ and an annual outbound water volume of $765 \times 10^{8} \mathrm{~m}^{3}$ [27]. There are seven cascade hydropower plants on the Lancang River, including the Gongguoqiao (GGQ), Xiaowan (XW), Manwan (MW), Dachaoshan (DCS), Nuozhadu (NZD), Jinghong (JH), and Ganlanba (GLB) power plants. The lower reaches of the Lancang River include three hydropower plants: namely, NZD, $\mathrm{JH}$, and GLB. The NZD hydropower plant has a multi-year regulation capacity, and its comprehensive utilization tasks are mainly for power generation, irrigation, flood control, shipping, ecology, tourism, etc. The JH hydropower plant is located $5 \mathrm{~km}$ away from the northern suburb of Jinghong city, and its main task is power generation, taking shipping, flood control, tourism, etc. into account. GLB is the reverse regulation power plant of the $\mathrm{JH}$ hydropower plant, and its main task is power generation, taking the needs of shipping and ecological water into account [28].

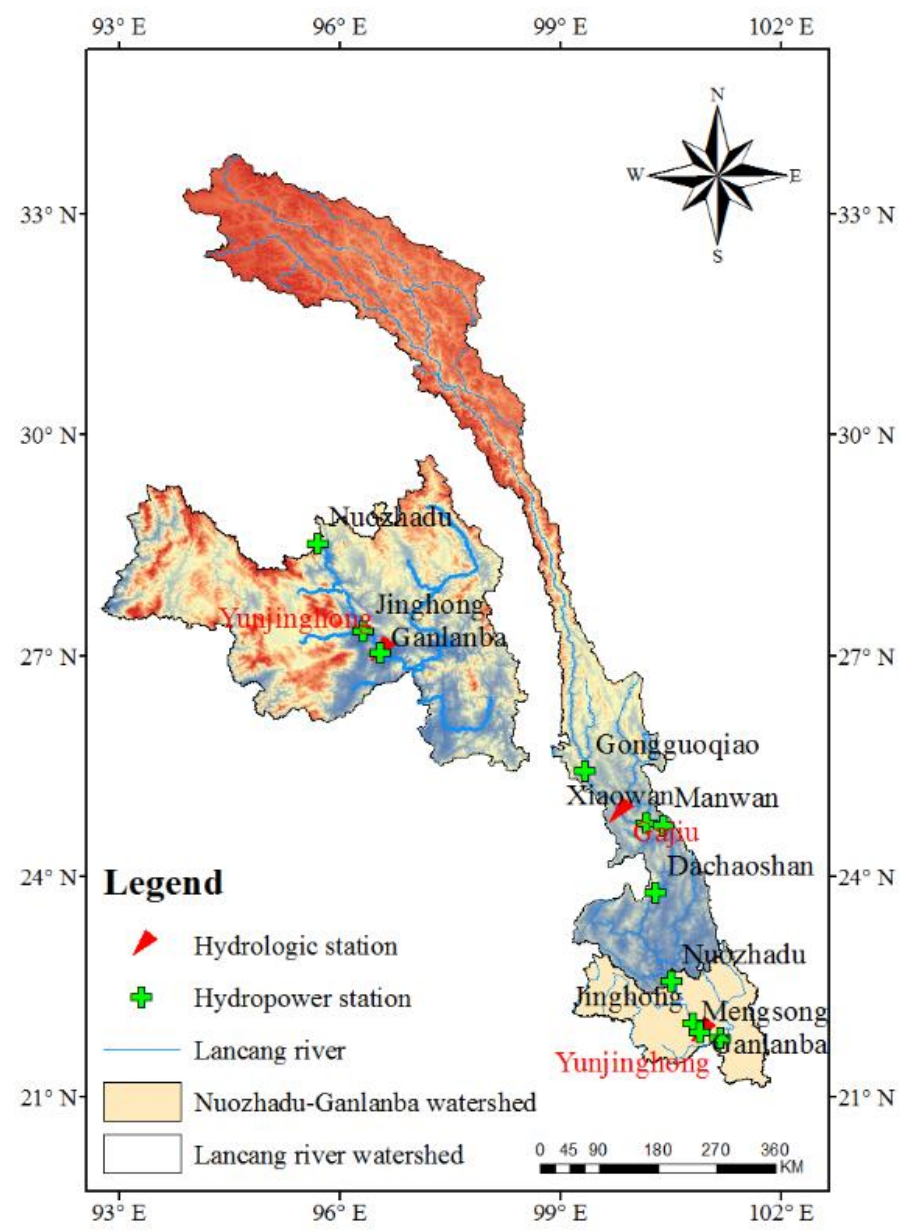

Figure 1. The location of the Lancang River.

In this study, the natural monthly runoff of the NZD and JH hydropower plants from 1953 to 2013 and the natural daily runoff (1953-2013) collected from the Yunjinghong hydrological station and the Huaneng Lancang River Hydropower Co., Ltd. (Kunming, China) were used to investigate and derive the hydropower plant operation. And the location of hydrological stations and hydropower plants were shown in Figure 2. 


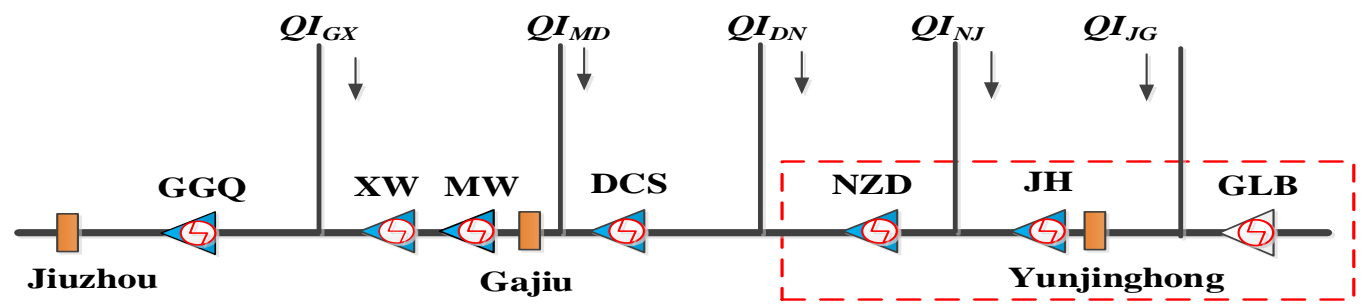

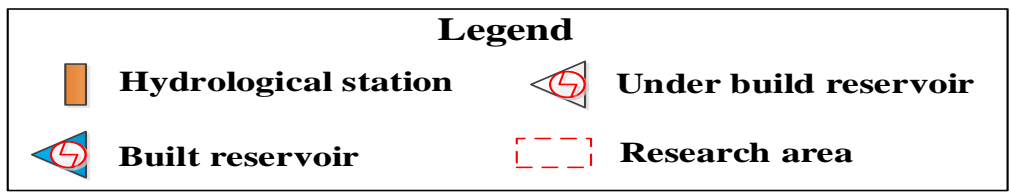

Figure 2. Network of the mainstream hydropower plants in the Lancang River.

\section{Methods}

In this section, we run through the details of the proposed methodology, including the copula joint function, Gibbs simulation model, and the constructed stochastic operation model. Figure 3 demonstrates the framework of the main research content in this paper.

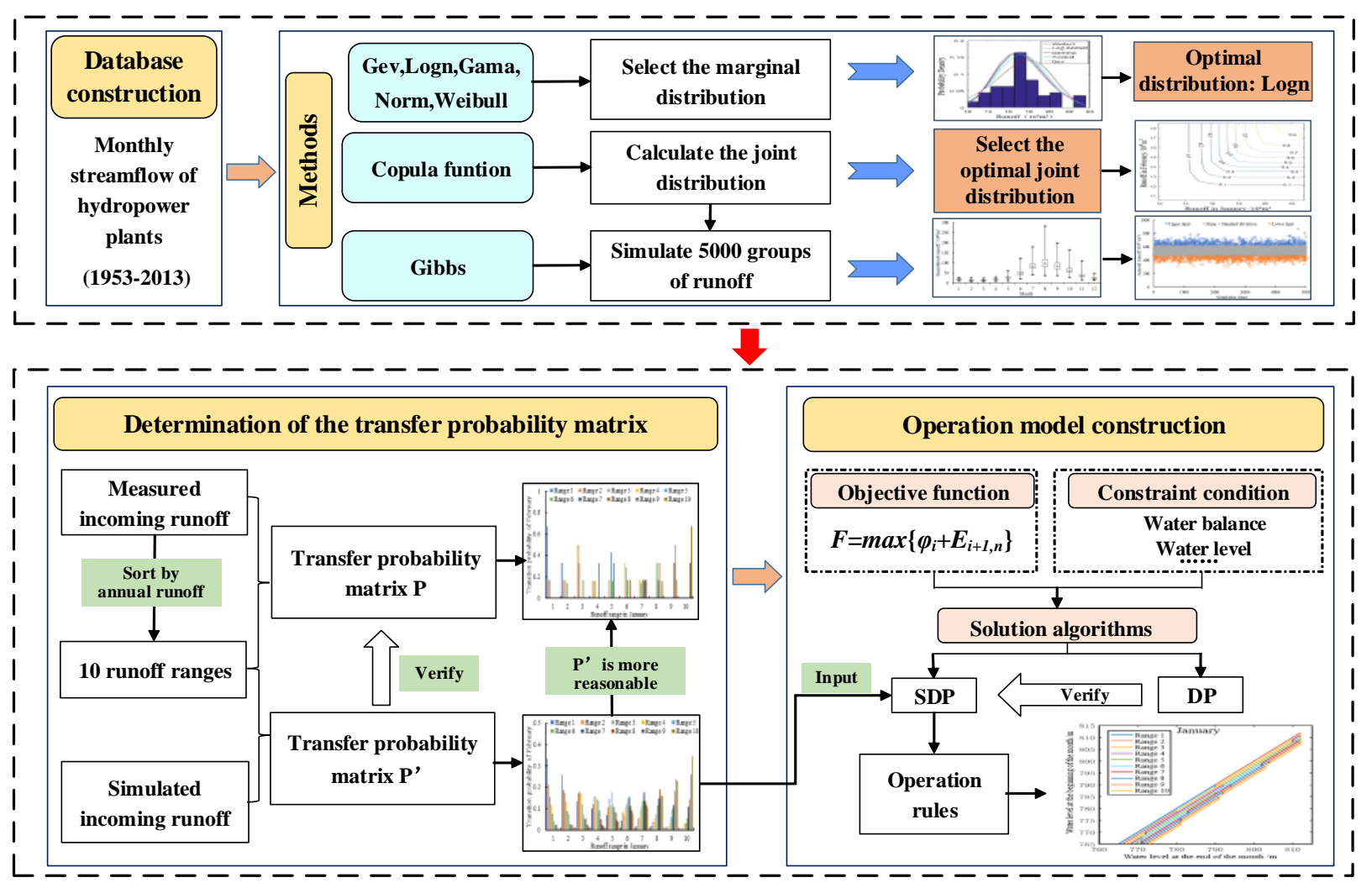

Figure 3. The framework of the main research content.

\subsection{Construction of Joint Distribution Model for Monthly Runoff}

3.1.1. Marginal Distribution Model of Incoming Runoff

In this paper, generalized extreme value distribution (Gev), logarithmic normal distribution (Logn), gamma distribution (Gamma), normal distribution (Norm), and weibull distribution (Weibull) were selected as the candidate marginal distributions of measured incoming runoff sequence [29-31]. The above probability distributions were chosen because they have the advantages of strong adaptability and a good fit, and they are widely used 
in the construction of marginal distribution models for frequency analysis of hydrological events. The probability density functions are listed here as follows:

Probability density function for Gev distribution:

$$
f(x / \mu, \sigma, \xi)=\sigma^{-1}\left[1+\xi\left(\frac{x-\mu}{\sigma}\right)\right]^{-\frac{1}{\zeta}-1} \exp \left\{\left[1+\xi\left(\frac{x-\mu}{\sigma}\right)\right]^{-\frac{1}{\zeta}}\right\}
$$

Probability density function for Logn distribution:

$$
f(x / \mu, \sigma)=\frac{1}{\sigma \sqrt{2 \pi}} \exp \left(-\frac{(\ln x-\mu)^{2}}{2 \sigma^{2}}\right)
$$

Probability density function for Gamma distribution:

$$
f(x / \alpha, \beta)=\frac{1}{\beta^{\alpha} \Gamma(\alpha)} x^{\alpha-1} \exp \left(\frac{-x}{\beta}\right)
$$

Probability density function for Norm distribution:

$$
f(x / \mu, \sigma)=\frac{1}{\sigma \sqrt{2 \pi}} \exp \left(-\frac{(x-\mu)^{2}}{2 \sigma^{2}}\right)
$$

Probability density function for Weibull distribution:

$$
f(x / \lambda, k)=\frac{k}{\lambda}\left(\frac{x}{\lambda}\right)^{k-1} e^{-(x / \lambda)^{k}}, x \geq 0
$$

where $\mu$ is average, $\sigma$ is standard deviation, $\xi, \alpha$, and $k$ represent shape parameters, $\beta$ and $\lambda$ represent scale parameters, and $x$ is the independent variable.

\subsubsection{Joint Distribution Model of Adjacent Monthly Incoming Runoff}

The introduction of the copula function caused a technological innovation in the field of hydrology, which could solve the multivariate frequency problem [32-34].

Supposing $X, Y$ represent the adjacent monthly incoming runoff, the corresponding designed values are $\mathrm{x}, \mathrm{y}$, and the marginal distributions are $F_{X}(x), F_{Y}(y)$. According to Sklar's theorem, the joint distribution of $X, Y$ can be described by the 2-D copula function $C$ :

$$
F(x, y)=C_{\theta}\left(F_{X}(x), F_{Y}(y)\right)
$$

where, $F(x, y)$ is the joint distribution of $\mathrm{X}, \mathrm{Y} ; \theta$ is the parameter of the copula function.

There are a great many types of copula functions, among which the Archimedean copula is widely used in the field of hydrology. In this chapter, 3 commonly used Archimedean copula functions (Gumbel copula, Clayton copula, and Frank copula) were selected to construct the joint distribution model of the monthly runoff in the NZD reservoir [35-37], the function is described as follows:

Gumbel copula:

$$
C(u, v)=\exp \left\{-\left[(-\ln u)^{\theta}+(-\ln v)^{\theta}\right]^{1 / \theta}\right\}
$$

Clayton copula:

$$
C(u, v)=\left(u^{-\theta}+v^{-\theta}-1\right)^{-1 / \theta}
$$

Frank copula:

$$
C(u, v)=-\frac{1}{\theta} \ln \left[1+\frac{\left.e^{-\theta u}-1\right)\left(e^{-\theta v}-1\right)}{\left(e^{-\theta}-1\right)}\right]
$$

where $u$ and $v$ represent marginal distribution function, namely $u=F_{X}(x), v=F_{Y}(y)$. 


\subsection{Stochastic Simulation Model of Runoff}

Gibbs sampling is a kind of Markov method, and the sampling process is as follows: each variable is sampled from the conditional distribution of other variables in a fixed order, a Markov chain converging to the target probability distribution is constructed, and samples are extracted from the chain [38,39].

Calculating conditional distribution by copula function:

$$
F_{i}\left(x_{i+1} / x_{i}\right)=\partial C_{i, i+1}\left(x_{i}, x_{i+1}\right) / \partial x_{i}, i=1,2 \cdots, 12
$$

The Gibbs sampling method is used for random simulation of the monthly runoff, and the steps are as follows:

(1) Generate 2 random numbers, $\mathrm{a}_{0}, a_{1} \in(0,1)$.

(2) $P\left(X_{1,1} \leq x_{1,1} / X_{2,1}=a_{0}\right)=\partial C\left(x_{1,1}, x_{2,1}\right) / \partial x_{2,1}=a_{1}, X_{i, j}$ represents the monthly runoff in the $i$ month of the $j$ year, according to the formula of conditional distribution, derive $v$, namely $x_{1,1}$.

(3) Generate 12 random numbers $a_{2}, a_{3}, \cdots, a_{13} \in(0,1)$ and solve the following equations:

$$
\left\{\begin{array}{c}
P\left(X_{2,1} \leq x_{2,1} / X_{1,1}=x_{1,1}\right)=\partial C\left(x_{1,1}, x_{2,1}\right) / \partial x_{1,1}=a_{2} \\
P\left(X_{3,1} \leq x_{3,1} / X_{2,1}=x_{2,1}\right)=\partial C\left(x_{2,1}, x_{3,1}\right) / \partial x_{2,1}=a_{3} \\
\vdots \\
P\left(X_{12,1} \leq x_{12,1} / X_{11,1}=x_{11,1}\right)=\partial C\left(x_{11,1}, x_{12,1}\right) / \partial x_{11,1}=a_{12} \\
P\left(X_{1,2} \leq x_{1,2} / X_{12,1}=x_{12,1}\right)=\partial C\left(x 1_{2,1}, x_{1,2}\right) / \partial x_{12,1}=a_{13}
\end{array}\right.
$$

The monthly runoff in all 12 months of the first year and January of the second year are obtained $\left(x_{1,1}, x_{2,1}, \cdots, x_{12,1}, x_{1,2}\right)$.

(4) Repeat step (3) for $\mathrm{n}$ times to obtain n-year simulated monthly runoff.

\subsection{Construction of Stochastic Operation Model and Solution}

\subsubsection{Objective Function}

Using 5000 groups of stochastic simulated runoff of the NZD hydropower plant, the stochastic optimal operation model of cascade hydropower plants in the lower reaches of the Lancang River was constructed with the objective of maximizing the power generation.

$$
F=\max \left\{\phi_{t}+E_{t+1, n}\right\}
$$

where $F$ is the generation expectation from time $t$ to time $n ; \phi_{t}$ is the power generation at time $t ; E_{t+1, n}$ is the generation expectation from $t+1$ to $n$, namely, the generation expectation in the remaining period.

\subsubsection{Constraint Condition}

The main constraints of these models are described as follows $[3,26]$ :

a. Water balance constraint:

$$
V_{t}=V_{t-1}+\left(q_{t}-Q_{t}\right) \cdot \Delta t-S_{t}
$$

b. Discharge constraint:

$$
Q_{t, \min } \leq Q_{t} \leq Q_{t, \max }
$$

c. Water level constraint:

$$
Z_{t, \min } \leq Z_{t} \leq Z_{t, \max }
$$

d. Output constraint:

$$
N_{\text {min }} \leq N_{t} \leq N_{\text {max }}
$$


e. The minimum ecological flow constraints:

$$
Q_{t} \leq \operatorname{base}_{(i, t)}
$$

f. The minimum shipping flow constraints:

$$
Q_{t} \leq Q_{t}^{e}
$$

where $V_{t-1}$ is the initial storage capacity, and $V_{t}$ is the final storage capacity; $q_{t}$ represents incoming runoff, $Q_{t}$ represents the discharge, and $S_{t}$ represents waste water; $Q_{t \min }$ and $Q_{t \text { max }}$ are the minimum and the maximum discharge; $Z_{t}, Z_{t, \min }$, and $Z_{t, \max }$ are, respectively, the hydropower plant's water level at month $t$, dead water level, and the highest water level of hydropower plant $i ; N_{t}, N_{\min }$, and $N_{\max }$ are, respectively, the hydropower plant output at month $t$, firm output, and the installed capacity; base $(i, t)$ is the ecological base flow at month $t$ of hydropower plant $i$; and $Q_{t}$ is the minimum flow for shipping.

\subsubsection{Solution Algorithm}

The SDP algorithm [40-42] was used to solve the stochastic operation model. When the SDP is applied to reservoir optimal operation, the runoff process is described by Markov chain, combined with the runoff forecast in the current period, and the incoming runoff in the future period is expressed by transfer probability. Therefore, the power generation in the current period can only be calculated according to the forecast runoff in the current period, and the power generation in the future period is represented by the power generation expectation.

The operation period (monthly) was taken as the stage variable, the water level of the NZD reservoir was divided with the accuracy of $1 \mathrm{~m}$, the water level $Z_{b . t}$ at the beginning of the month was taken as the state variable, and the water level $Z_{e, t}$ at the end of the month was taken as the decision variable. The water balance equation was used as the state transition equation.

Setting the runoff in period $t$ as $q_{t, 1}, q_{t, 2}, \cdots q_{t, n}(n=10)$, and the transfer probability matrix from period $t$ to period $t+1$ is as follows:

$$
P_{i j t}=\left[\begin{array}{cccc}
P_{11 t} & P_{12 t} & \cdots & P_{1 n t} \\
P_{21 t} & P_{22 t} & \cdots & P_{2 n t} \\
\vdots & \vdots & & \vdots \\
P_{n 1 t} & P_{n 2 t} & \cdots & P_{n n t}
\end{array}\right]
$$

Assuming that the incoming runoff $q_{t, i}$ at $k$ period has been given, the formula of optimal power generation expectation is as follows:

$$
f_{t}^{*}\left(Z_{b, t}, q_{t, i}\right)=\max \left\{\Phi_{t}\left(Z_{b, t}, Z_{e, t}, q_{t, i}\right)+\sum_{j=1}^{n} p_{i j t} f_{t+1}^{*}\left(Z_{e, t}, q_{t+1, j}\right)\right\}(t=1,2, \cdots n)
$$

where $f_{t}^{*}\left(Z_{b, t}, q_{t, i}\right)$ represents the generation expectation at time $t ; \Phi_{t}\left(Z_{b, t}, Z_{e, t}, q_{t, i}\right)$ represents the power generation at time $t ; Z_{b, t}$ is the water level at the beginning of the month; $Z_{e, t}$ is the water level at the end of the month; $q_{t, i}$ is the amount of runoff at time $t ; i \in(1,10), p_{i j t}$ represents the transfer probability matrix from period $t$ to period $t+1 ; j \in(1,10), f_{t+1}^{*}\left(Z_{e, t}, q_{t+1, j}\right)$ represents the generation expectation at time $t+1$; and $q_{t+1, j}$ is the amount of runoff at time $t+1$.

Regardless of the initial state and initial decision, for the state formed by the previous decision, the other decisions must constitute the optimal strategy: that is, the n-dimensional optimization problem must be transferred into $\mathrm{n}$ 1-dimensional problems. Compared with the DP algorithm, the difference of the SDP is that the incoming runoff is a stochastic process. 


\section{Results and Discussion}

\subsection{Stochastic Simulation of Runoff}

\subsubsection{Marginal Distribution for Incoming Runoff}

It was concluded from the cumulative frequency (in Figure 4) that the 5 selected distribution curves (Weibull, Log-normal, Gamma, Normal and Gev) fit well with the curve of the experience frequency. The K-S test, AIC, and RSME were adopted to quantitatively evaluate the fitting effect of the marginal distribution, and the results are shown in Table 1 (the optimal marginal distribution is bolded). It is clearly found from Table 1 that for the K-S test, there were 8 months where the corresponding optimal distribution was Logn distribution (the optimal distribution of January, February, and April was GEV distribution, and that of May was Gamma distribution); similarly, for the AIC and EMSE there were 7 months and 9 months, respectively, where the optimal distribution was Logn distribution. Overall, the Logn was the best distribution of the five distributions. Therefore, the Logn distribution was selected as the monthly marginal distribution of the incoming runoff sequence.

\subsubsection{Copula Joint Distribution for Incoming Runoff}

The copula function is used to derive the joint function between adjacent monthly runoff. The parameters of three candidate copula functions were estimated by the maximum likelihood method, and the copula function was selected using AIC criterion. The results are shown in Table 2. The bold AIC values in the table indicate the optimal copula function. The Frank copula was selected in January-February, February-March, and December-January; the Gumbel copula was selected in March-April, May-June, June-July, and July-August; and the Clayton copula was selected for other months.

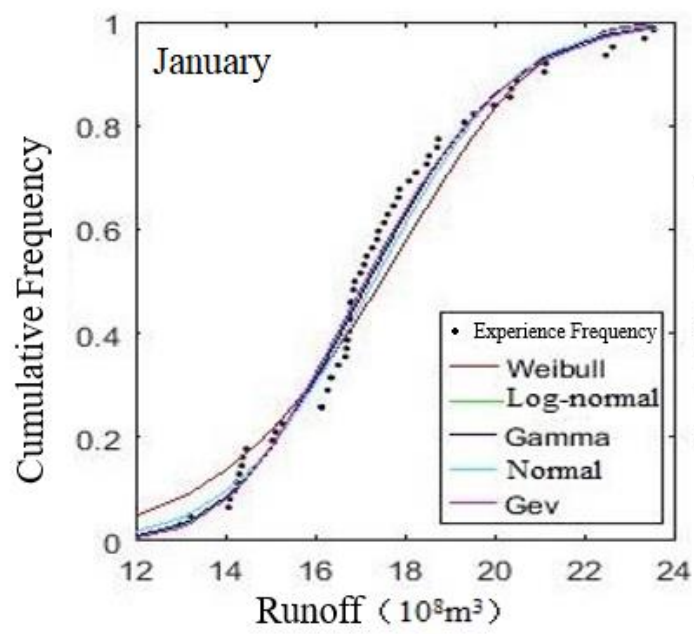

Figure 4. Cont.

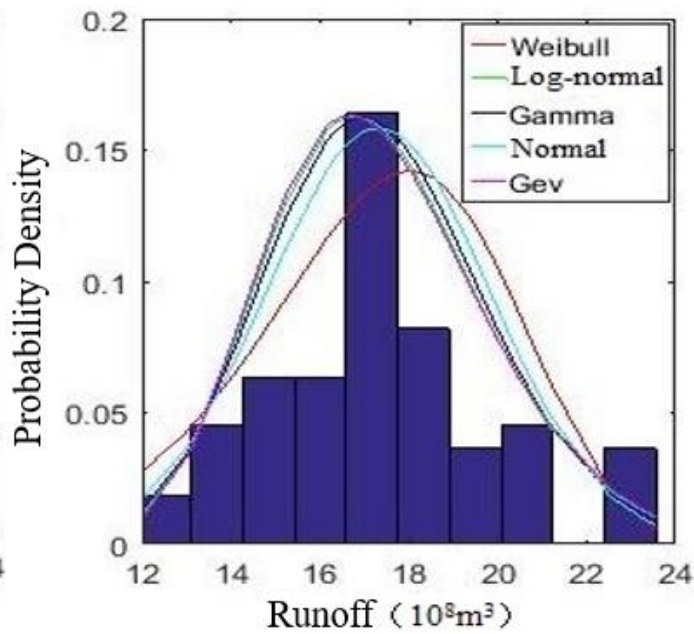



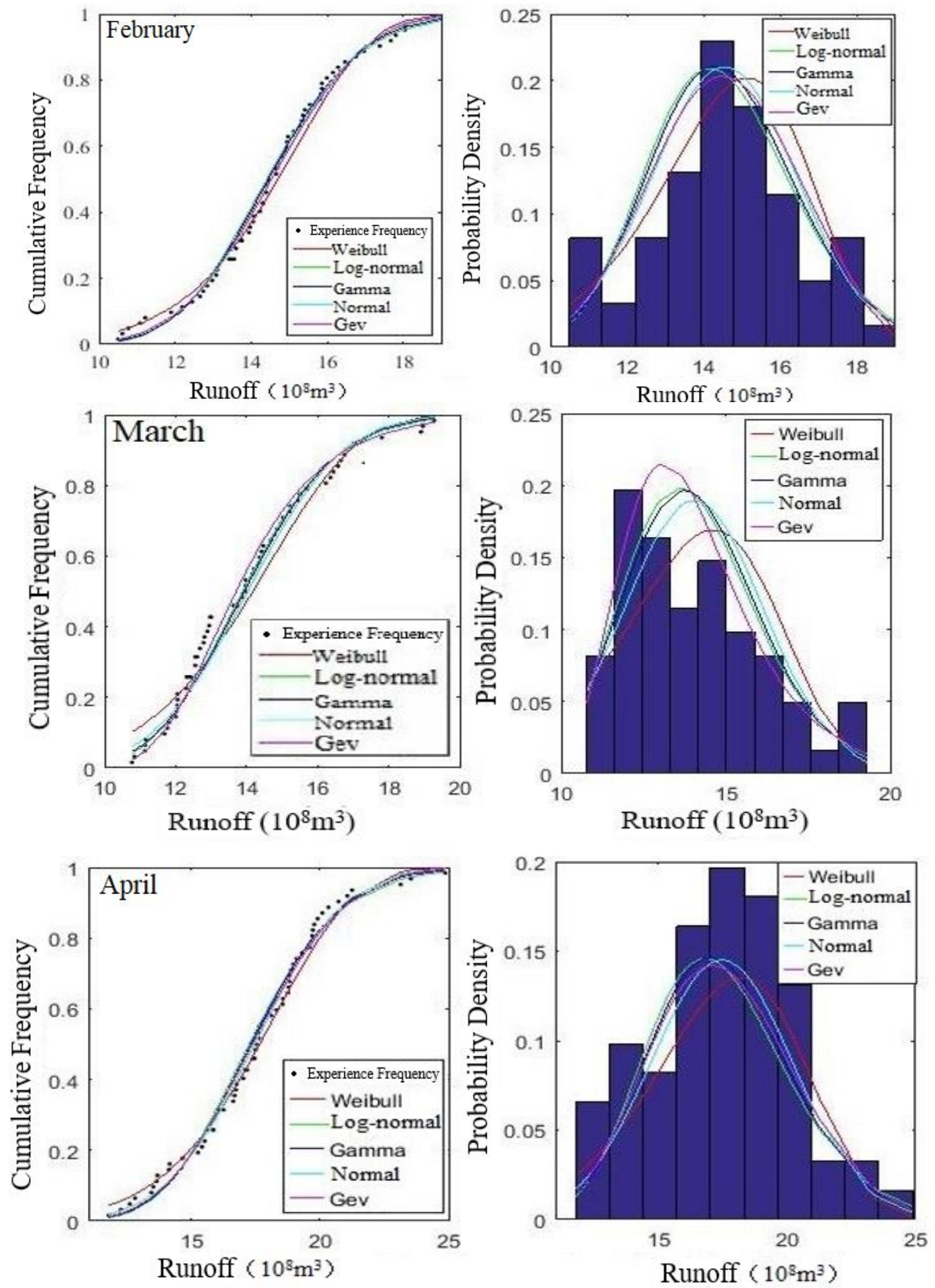

Figure 4. Cont. 

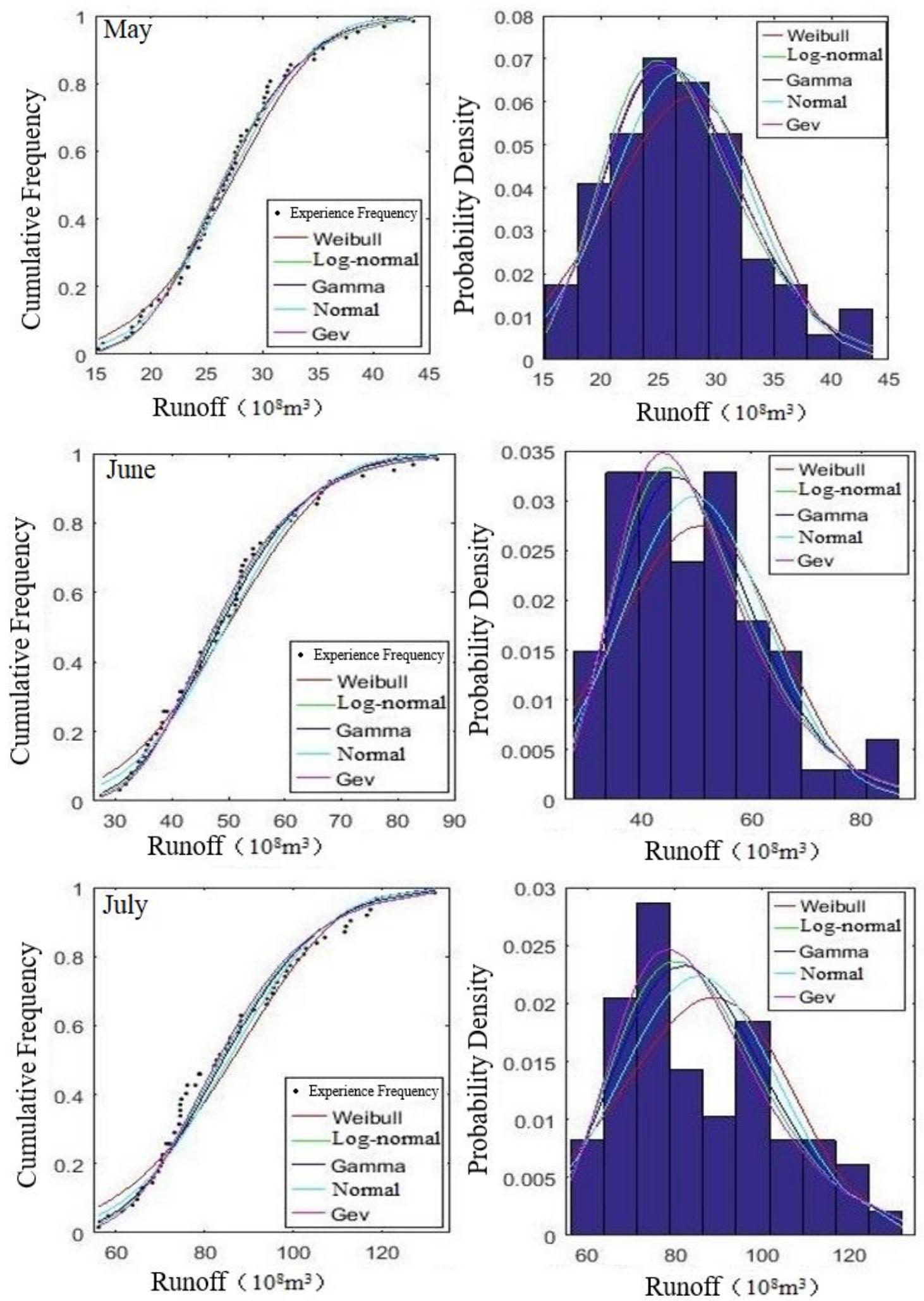

Figure 4. Cont. 

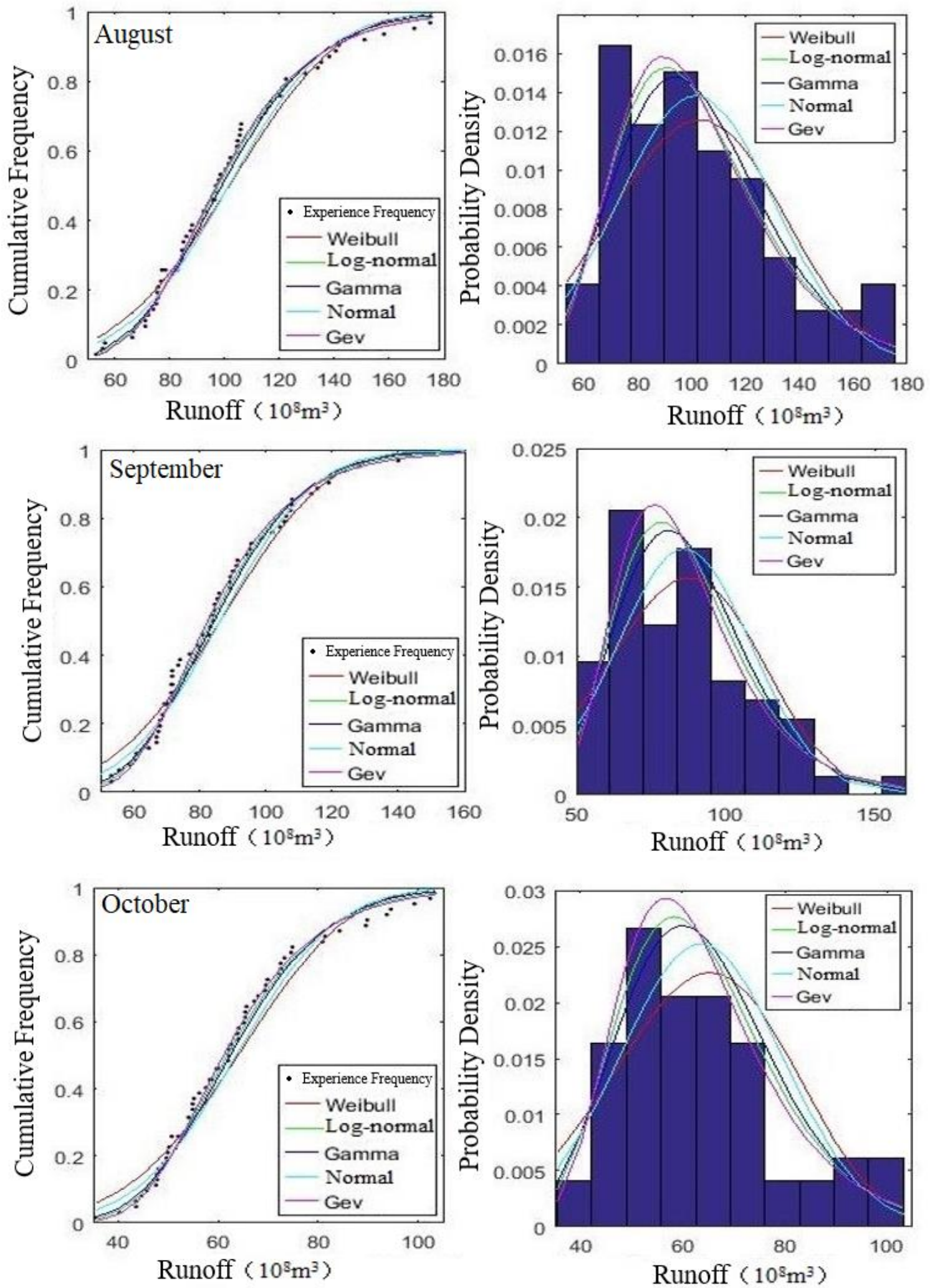

Figure 4. Cont. 

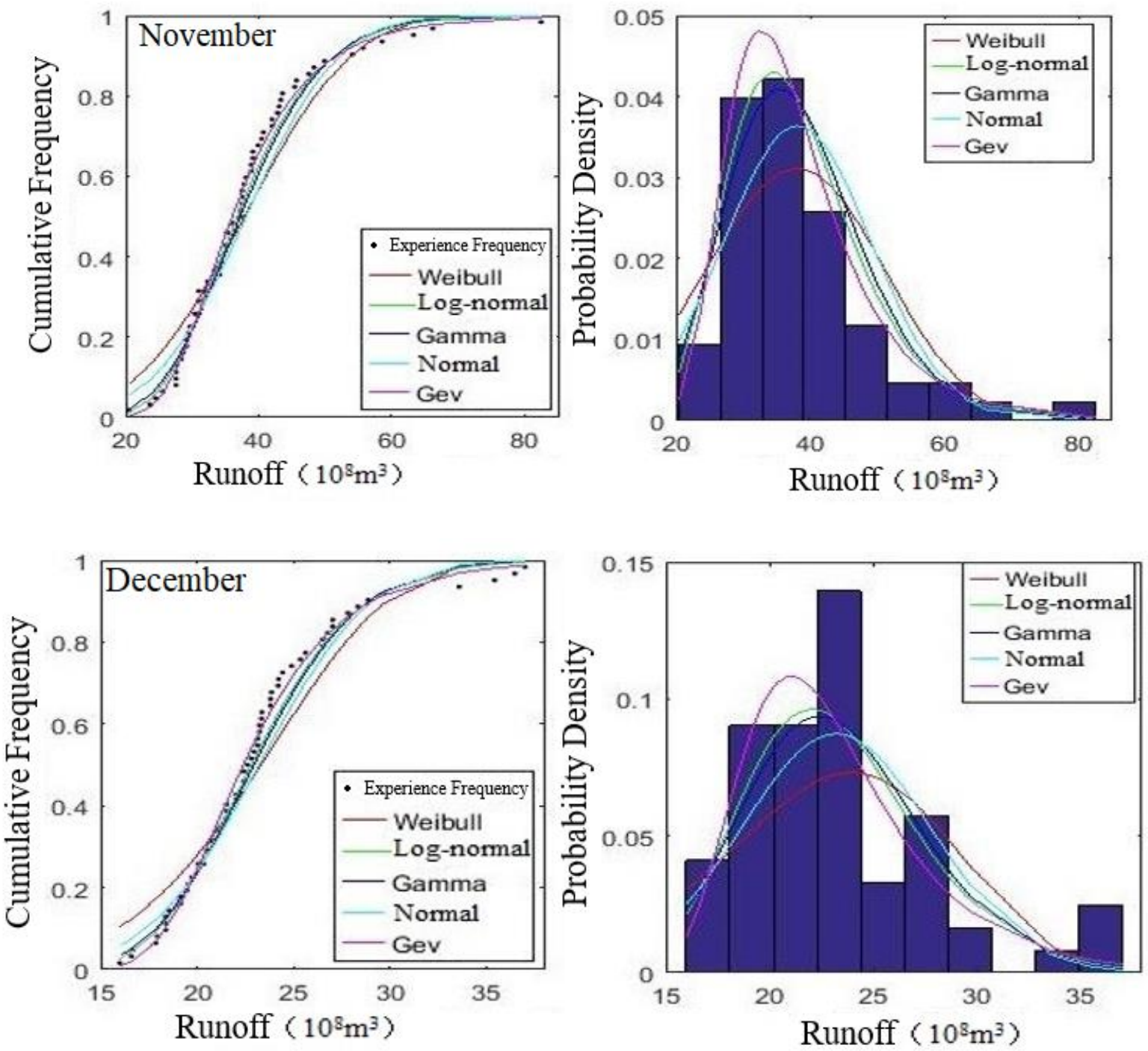

Figure 4. Cumulative frequency and probability density for runoff of the NZD hydropower plant.

Table 1. K-S, AIC, and RMSE of incoming runoff in the NZD reservoir.

\begin{tabular}{|c|c|c|c|c|c|c|c|}
\hline Index & Distribution & January & February & March & April & May & June \\
\hline \multirow{5}{*}{ K-S test } & Weibull & 0.240 & 0.749 & 0.314 & 0.854 & 0.539 & 0.420 \\
\hline & Logn & 0.449 & 0.895 & 0.369 & 0.774 & 0.954 & 0.975 \\
\hline & Gamma & 0.531 & 0.958 & 0.315 & 0.888 & 0.970 & 0.954 \\
\hline & Norm & 0 & 0 & 0 & 0 & 0 & 0 \\
\hline & Gev & 0.602 & 0.999 & 0.235 & 0.994 & 0.863 & 0.598 \\
\hline \multirow{5}{*}{ AIC } & Weibull & 296.555 & 257.53 & 275.016 & 303.779 & 397.945 & 493.377 \\
\hline & Logn & 286.587 & 255.956 & 262.653 & 300.312 & 392.247 & 483.081 \\
\hline & Gamma & 286.931 & 255.069 & 263.75 & 299.536 & 391.855 & 484.338 \\
\hline & Norm & 288.843 & 254.317 & 266.92 & 299.446 & 393.985 & 490.282 \\
\hline & Gev & 288.81 & 256.575 & 263.048 & 301.98 & 394.265 & 485.293 \\
\hline \multirow{5}{*}{ RMSE } & Weibull & 0.062 & 0.035 & 0.054 & 0.029 & 0.038 & 0.044 \\
\hline & Logn & 0.04 & 0.029 & 0.038 & 0.037 & 0.025 & 0.022 \\
\hline & Gamma & 0.041 & 0.025 & 0.039 & 0.032 & 0.021 & 0.025 \\
\hline & Norm & 0.046 & 0.02 & 0.045 & 0.024 & 0.025 & 0.038 \\
\hline & Gev & 0.306 & 0.316 & 0.302 & 0.302 & 0.275 & 0.262 \\
\hline
\end{tabular}


Table 1. Cont.

\begin{tabular}{|c|c|c|c|c|c|c|c|}
\hline Index & Distribution & July & August & September & October & November & December \\
\hline \multirow{5}{*}{ K-S test } & Weibull & 0.364 & 0.229 & 0.471 & 0.373 & 0.15 & 0.104 \\
\hline & Logn & 0.535 & 0.915 & 0.697 & 0.977 & 0.85 & 0.67 \\
\hline & Gamma & 0.431 & 0.722 & 0.624 & 0.907 & 0.606 & 0.498 \\
\hline & Norm & 0 & 0 & 0 & 0 & 0 & 0 \\
\hline & Gev & 0.291 & 0.293 & 0.547 & 0.517 & 0.216 & 0.23 \\
\hline \multirow{5}{*}{ AIC } & Weibull & 531.949 & 588.492 & 560.242 & 516.981 & 472.988 & 371.753 \\
\hline & Logn & 523.338 & 578.995 & 547.004 & 505.39 & 451.806 & 351.651 \\
\hline & Gamma & 524.208 & 580.171 & 548.8 & 506.957 & 455.697 & 354.275 \\
\hline & Norm & 527.805 & 586.518 & 555.915 & 513.035 & 468.245 & 361.636 \\
\hline & Gev & 525.192 & 581.272 & 548.725 & 507.028 & 451.248 & 350.342 \\
\hline \multirow{5}{*}{ RMSE } & Weibull & 0.052 & 0.05 & 0.051 & 0.056 & 0.074 & 0.075 \\
\hline & Logn & 0.038 & 0.021 & 0.027 & 0.024 & 0.031 & 0.033 \\
\hline & Gamma & 0.041 & 0.028 & 0.033 & 0.032 & 0.041 & 0.04 \\
\hline & Norm & 0.049 & 0.047 & 0.047 & 0.049 & 0.064 & 0.056 \\
\hline & Gev & 0.281 & 0.255 & 0.266 & 0.269 & 0.265 & 0.29 \\
\hline
\end{tabular}

Table 2. Parameters and AIC of joint distribution of inflow in the NZD reservoir.

\begin{tabular}{ccccc}
\hline \multirow{2}{*}{ Monthly } & Parameters & \multicolumn{3}{c}{ Copula } \\
\cline { 2 - 5 } & & Clayton & Frank & Gumbel \\
\hline \multirow{2}{*}{ January-February } & $\theta$ & 2.84 & 12.11 & 2.99 \\
February-March & AIC & -74.30 & $-\mathbf{9 4 . 2 6}$ & -85.33 \\
& $\theta$ & 1.04 & 4.95 & 1.68 \\
March-April & AIC & -24.75 & $-\mathbf{2 9 . 7 9}$ & -25.47 \\
& $\theta$ & 0.94 & 4.93 & 1.78 \\
April-May & AIC & -19.82 & -29.76 & $-\mathbf{3 2 . 6 6}$ \\
& $\theta$ & 0.72 & 3.54 & 1.45 \\
May-June & AIC & $-\mathbf{1 5 . 0 8}$ & -15.07 & -11.72 \\
& $\theta$ & 0.60 & 2.07 & 1.29 \\
June-July & AIC & -6.74 & -4.90 & $-\mathbf{7 . 3 5}$ \\
& $\theta$ & 0.74 & 2.92 & 1.40 \\
July-August & AIC & -10.76 & -12.24 & $-\mathbf{1 2 . 7 2}$ \\
August-September & $\theta$ & 0.78 & 2.61 & 1.37 \\
September-October & AIC & -7.86 & -9.88 & $-\mathbf{1 1 . 7 8}$ \\
& $\theta$ & 1.09 & 3.60 & 1.50 \\
October-November & AIC & $-\mathbf{2 0 . 5 1}$ & -16.76 & -18.56 \\
November-December & $\theta$ & 0.87 & 2.94 & 1.34 \\
& AIC & $-\mathbf{1 3 . 8 1}$ & -11.10 & -9.92 \\
December-January & $\theta$ & 1.65 & 3.78 & 1.26 \\
& AIC & $-\mathbf{3 4 . 6 9}$ & -17.03 & -3.12 \\
& $\theta$ & 5.13 & 12.59 & 2.49 \\
& AIC & $-\mathbf{1 0 9 . 3 8}$ & -91.74 & -62.23 \\
& $\theta$ & 0.13 & 0.55 & 1.04 \\
& AIC & 1.43 & $\mathbf{1 . 5 5}$ & 1.62 \\
\hline
\end{tabular}

The contour map of the cumulative distribution function of the optimal copula function for each adjacent month is shown in Figure 5. In Figure 5, it is easy to obtain the probability that the incoming water in a certain month is within a certain magnitude and that the adjacent month's incoming water is within a certain magnitude. Through the joint distribution, the corresponding joint probability of the two adjacent months' incoming water can be obtained. It should work as well.

\subsubsection{Stochastic Simulation of Incoming Runoff}

Combined with the lognormal distribution and copula function, the Gibbs method was used to simulate monthly runoff. The simulated and measured runoff of the NZD 
reservoir are shown in Figure 6. It can be seen from the figure that the simulated monthly runoff distribution was highly consistent with the measured runoff distribution. The maximum value appeared in August and the minimum value appeared in March. The maximum value of the simulated runoff in each month was higher than the measured value, and the months with the largest deviation occurred in the wet season, especially in August. However, from the median value, it could be found that the median value of the simulated runoff and measured runoff were basically consistent. The multi-year average of the simulated runoff $\left(537.210^{8} \mathrm{~m}^{3} / \mathrm{s}\right)$ was $0.710^{8} \mathrm{~m}^{3} / \mathrm{s}$ less than the measured runoff $\left(537.910^{8} \mathrm{~m}^{3} / \mathrm{s}\right)$. The standard deviation of the simulated runoff $\left(73.2710^{8} \mathrm{~m}^{3} / \mathrm{s}\right)$ was reduced by $4.7110^{8} \mathrm{~m}^{3} / \mathrm{s}$ compared with the standard deviation of the measured runoff $\left(77.9810^{8} \mathrm{~m}^{3} / \mathrm{s}\right)$. According to the measured annual mean runoff of \pm 1 standard deviation as a reasonable range, the simulated annual runoff was statistically analyzed (in Figure 7). The proportion of the simulated annual runoff exceeding this range was $13.98 \%$, and the proportion lower than this range was $14.9 \%$. Most of the simulated runoff values were within this range, accounting for $71.12 \%$, showing the uncertainty of the incoming water process.
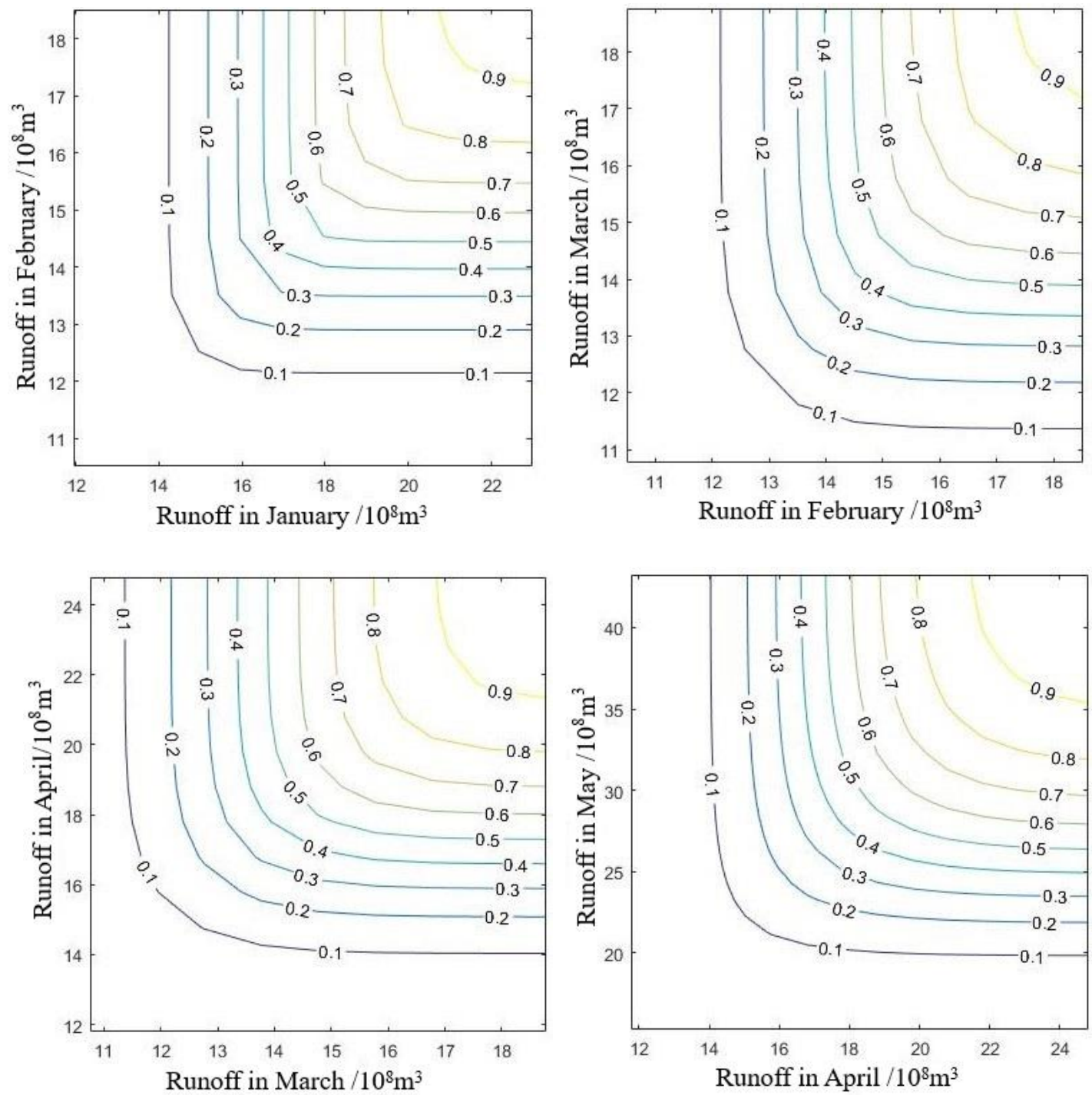

Figure 5. Cont. 

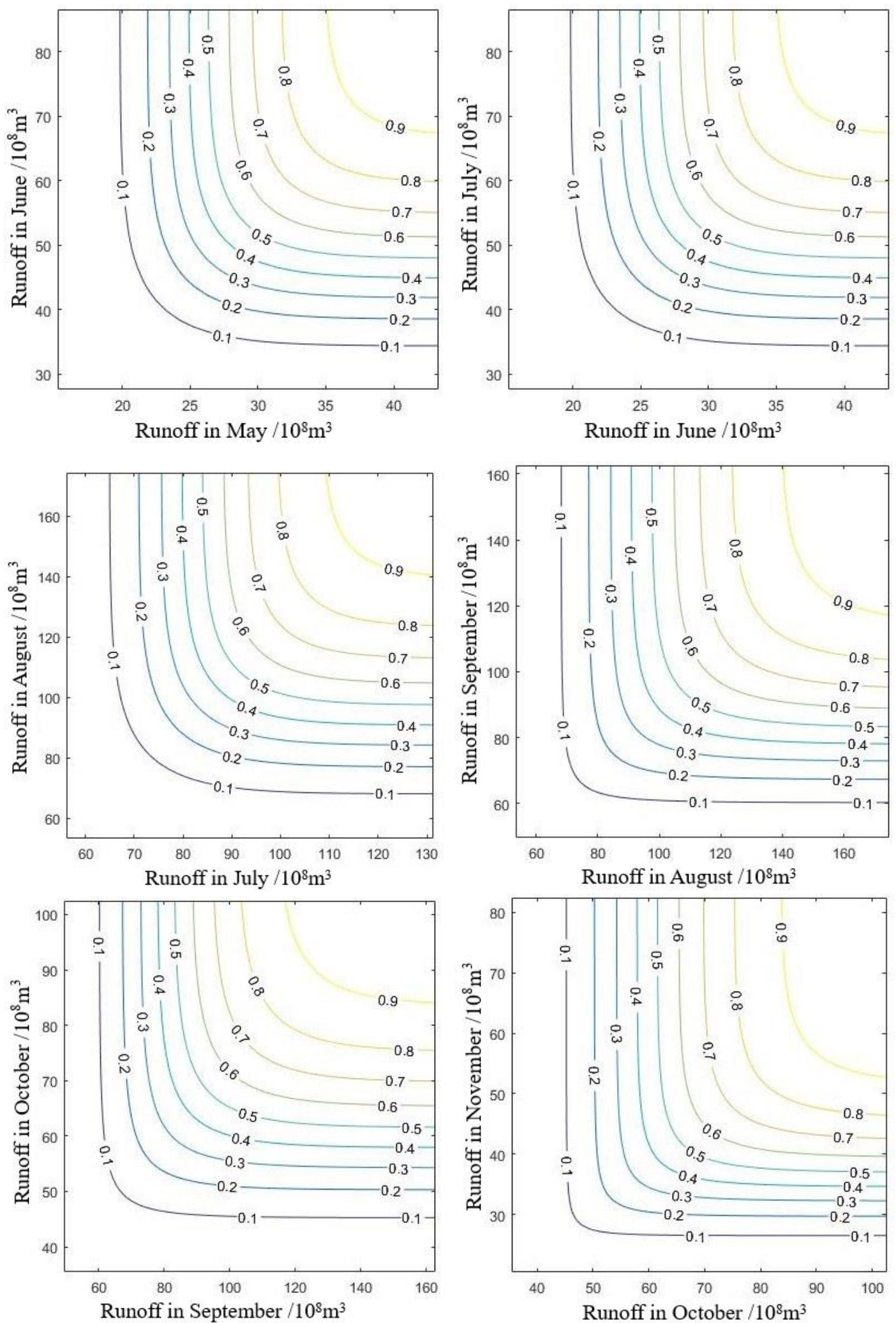

Figure 5. Cont. 

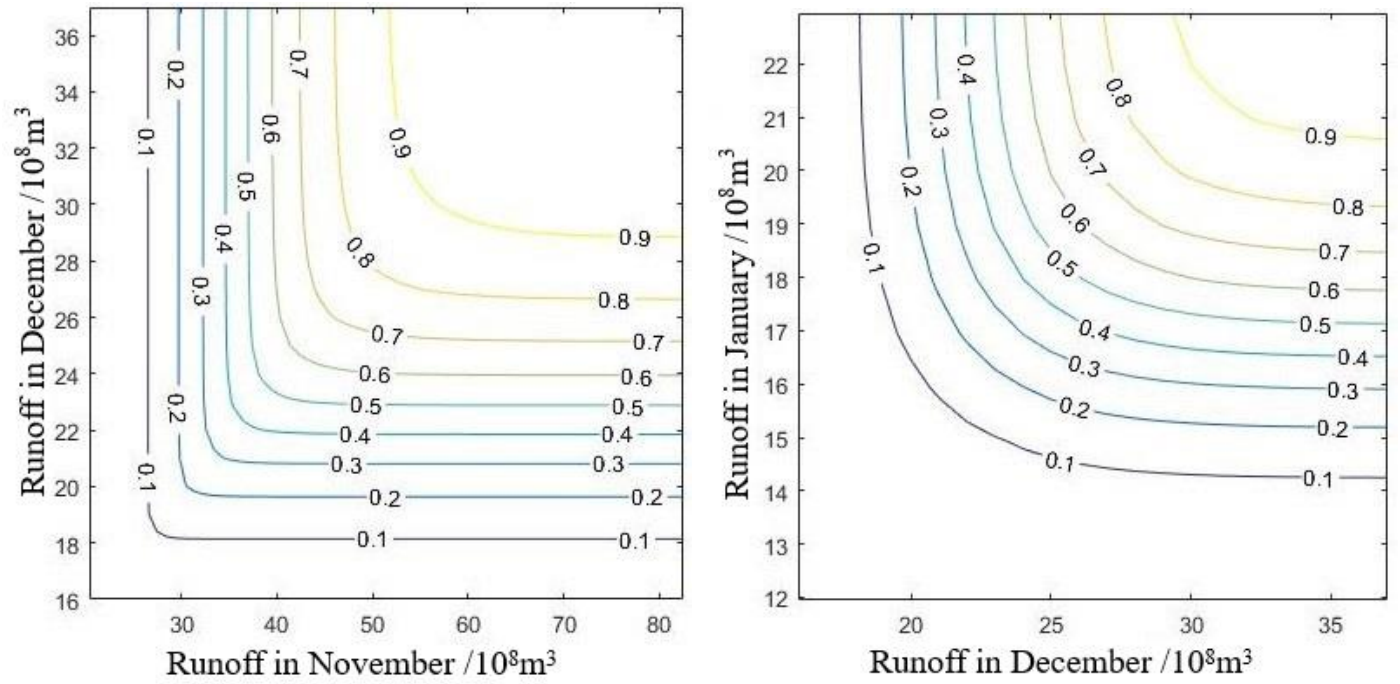

Figure 5. Joint probability distribution of incoming runoff in the NZD hydropower plant.
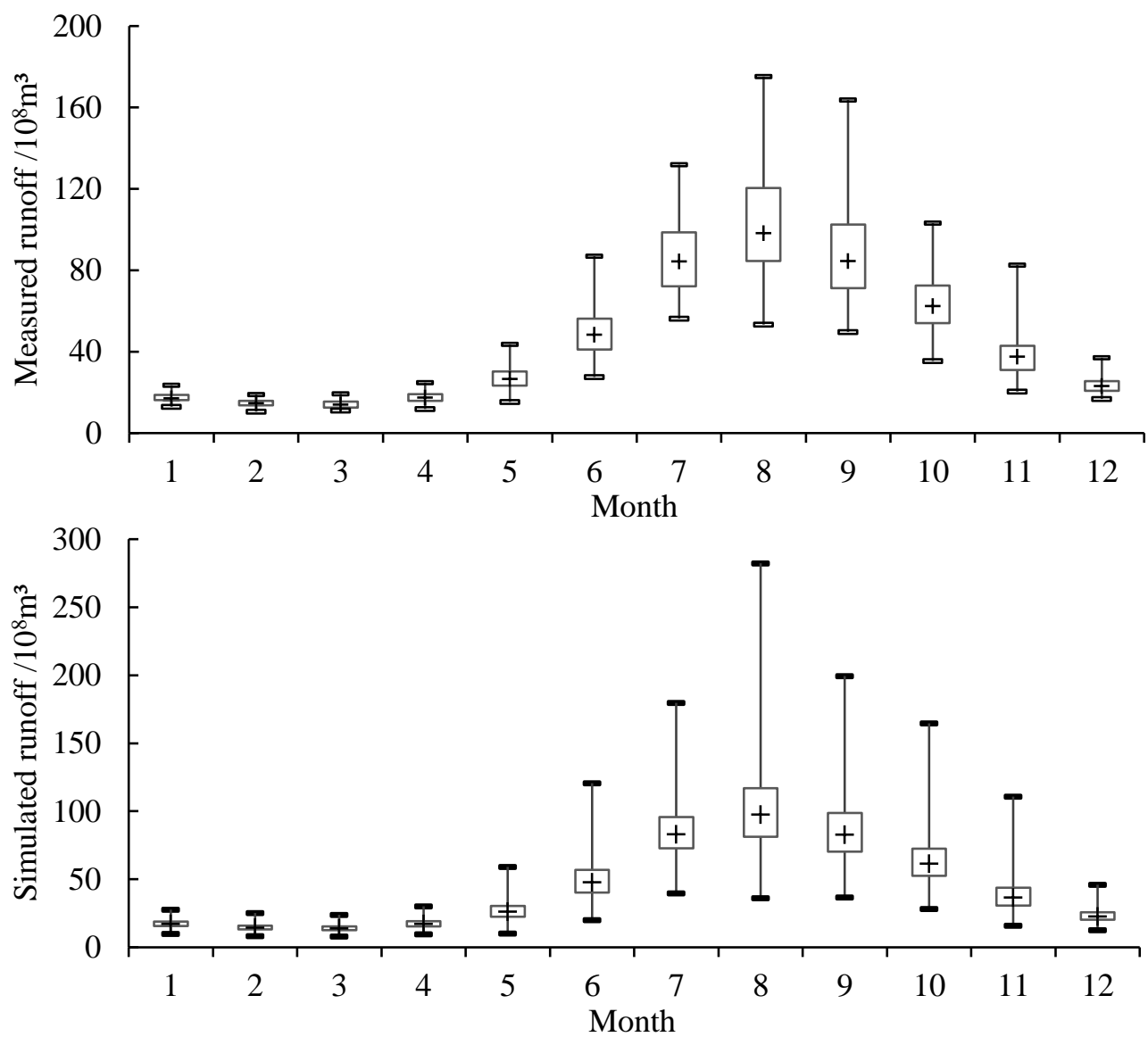

Figure 6. Observed and simulated monthly inflow of the NZD hydropower plant. 


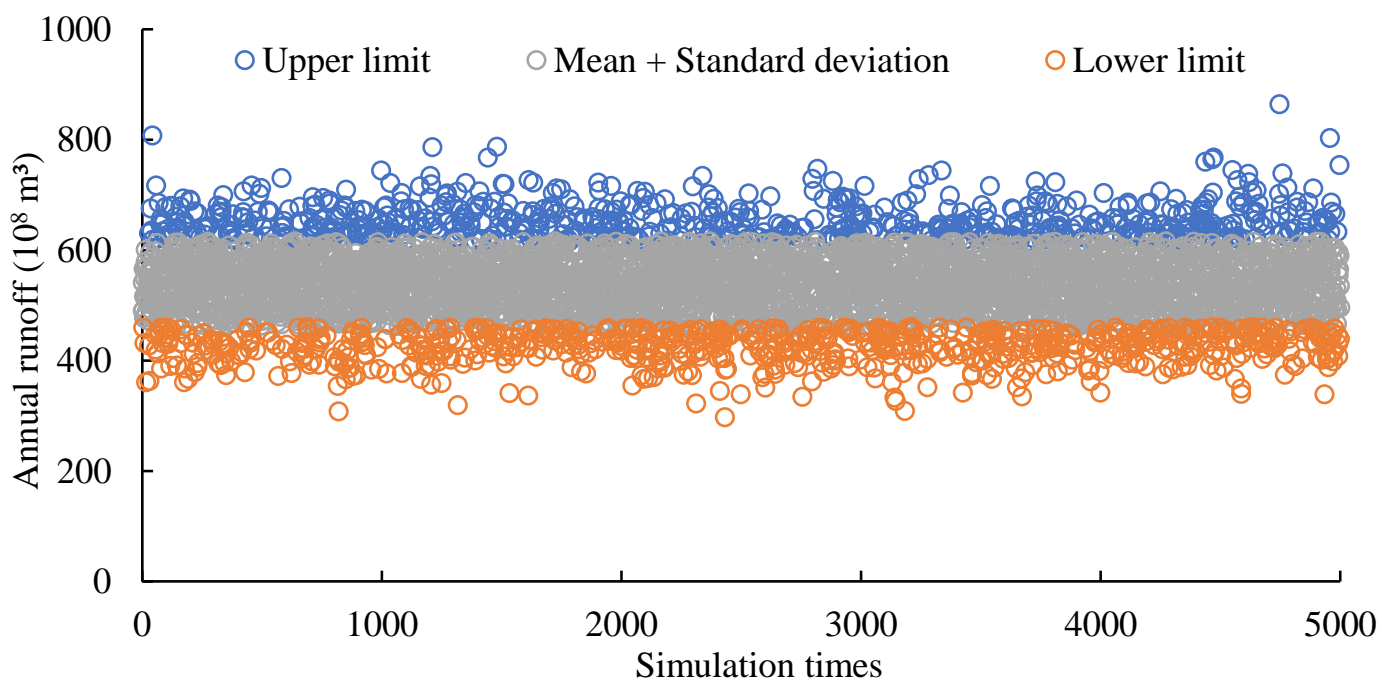

Figure 7. Simulated annual runoff of the NZD hydropower plant.

\subsection{Process of Incoming Runoff}

\subsubsection{Transfer Probability Matrix Based on Measured Runoff}

The monthly runoff of the NZD hydropower plant was sorted in descending order, 10 representative runoff $Q R(Q R 1$ representing the average of the runoff in $P \in(0,10 \%]$, $Q R 2$ representing for the average of runoff in $P \in(10 \%, 20 \%]$, etc.) were selected, and the runoff in each month under the same QR was plotted on the same curve (Figure 8).

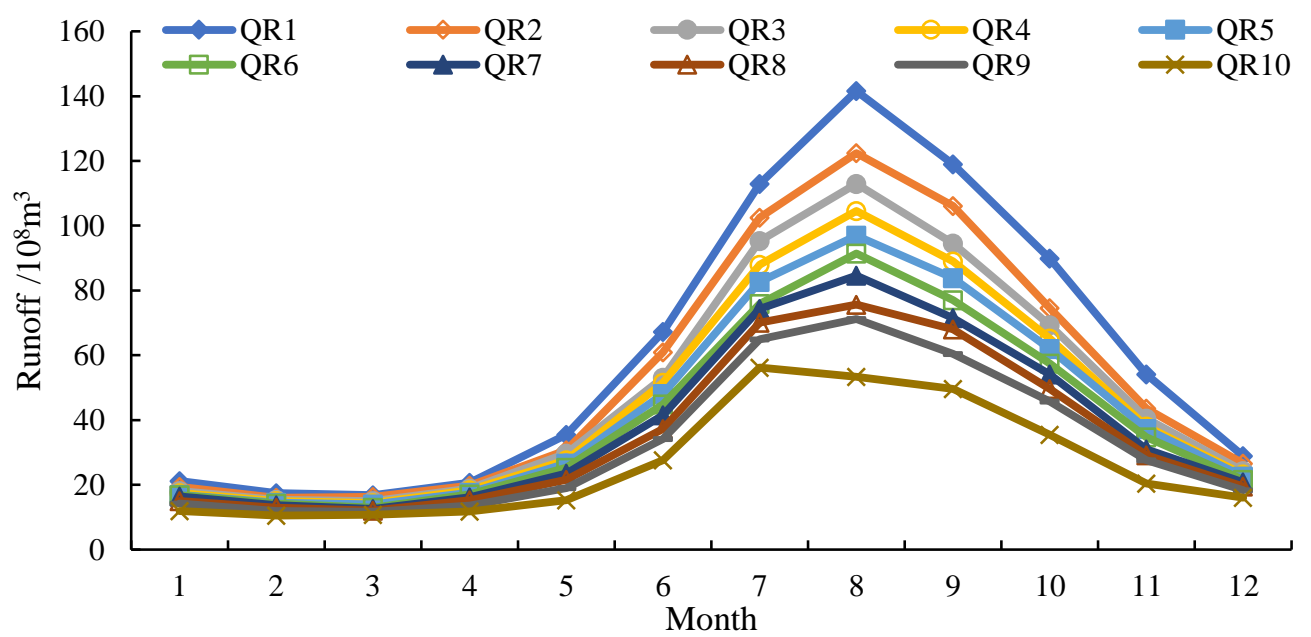

Figure 8. Representative runoff of each month.

Based on the monthly representative flow of the NZD hydropower plant (Table 3), the one-step transfer probability matrix of monthly runoff is derived. It could be seen from the transfer probability matrix (Figure 9) that because the measured runoff was limited (only 61 years from 1953 to 2013), the derived transfer probability matrix did not have obvious statistical regularity. For example, when the incoming runoff in June dropped into QR1, there were only three representative runoffs in July (QR1, QR4, and QR5), while the probability of incoming runoff for other representative runoffs was 0 . The transfer probability matrix of runoff was the important input of the stochastic optimal operation model. However, the transfer probability matrix based on measured runoff had the phenomenon of too many 0 values, which made it difficult to obtain reasonable optimal operation results. Therefore, the Gibbs method was used to generate a large number of samples to deal with the impacts of insufficient data on the transfer probability matrix. 
Table 3. Representative runoff in each month for measured runoff of the NZD hydropower plant $\left(10^{8} \mathrm{~m}^{3}\right)$.

\begin{tabular}{|c|c|c|c|c|c|c|c|c|c|c|}
\hline \multirow{2}{*}{ Month } & \multicolumn{10}{|c|}{ Representative Runoff QR } \\
\hline & 1 & 2 & 3 & 4 & 5 & 6 & 7 & 8 & 9 & 10 \\
\hline June & 67.2 & 60.9 & 53.1 & 51.5 & 48.1 & 44.9 & 41.5 & 37.3 & 34.1 & 27.6 \\
\hline July & 112.9 & 102.4 & 95.3 & 88.0 & 82.7 & 75.9 & 74.3 & 70.1 & 64.9 & 56.2 \\
\hline August & 141.6 & 122.4 & 112.9 & 104.5 & 96.9 & 91.4 & 84.6 & 75.6 & 71.2 & 53.3 \\
\hline September & 119.0 & 106.1 & 94.6 & 89.0 & 83.8 & 77.0 & 71.4 & 68.0 & 60.4 & 49.6 \\
\hline October & 89.8 & 74.6 & 69.3 & 65.1 & 62.0 & 57.5 & 54.1 & 49.6 & 45.7 & 35.5 \\
\hline November & 54.1 & 43.6 & 40.4 & 38.1 & 37.3 & 34.7 & 31.0 & 29.2 & 27.6 & 20.4 \\
\hline December & 28.9 & 26.5 & 24.2 & 23.2 & 22.6 & 21.5 & 20.8 & 19.5 & 18.4 & 16.0 \\
\hline January & 21.1 & 19.3 & 18.1 & 17.4 & 16.9 & 16.8 & 16.4 & 15.1 & 14.2 & 12.0 \\
\hline February & 17.4 & 16.0 & 15.4 & 14.9 & 14.5 & 14.2 & 13.7 & 13.0 & 11.9 & 10.5 \\
\hline March & 16.8 & 16.2 & 15.0 & 14.4 & 14.0 & 12.9 & 12.6 & 12.1 & 11.7 & 10.8 \\
\hline April & 20.7 & 19.7 & 18.8 & 18.3 & 17.5 & 17.0 & 16.1 & 15.3 & 13.5 & 11.8 \\
\hline May & 35.5 & 30.7 & 29.7 & 27.6 & 26.5 & 25.3 & 23.5 & 21.6 & 19.0 & 15.3 \\
\hline
\end{tabular}

\subsubsection{Transfer Probability Matrix based on Simulated Runoff}

In this paper, 5000 groups of stochastic runoff of the NZD hydropower plant were simulated based on the Gibbs method to derive the transfer probability matrix. The representative runoff in each month is shown in Table 4, and the one-step transfer probability matrix from June to May of the next year was obtained (Figure 10). Moreover, the phenomenon of centralized probability distribution and the transfer probability of 0 did not appear during the process of deriving the transfer probability matrix based on the simulated runoff. It was concluded that the transfer probability matrix based on simulated runoff could solve the problem of deficiency in measured runoff data.

\subsection{Result of Hydropower Plants Operation}

In this paper, the transfer probability matrix of the simulated runoff of the NZD reservoir was used as the input of the reservoir operation model, and the SDP algorithm was used to solve the model to obtain the operation results of the NZD reservoir under 10 representative runoffs. At the same time, taking the incoming runoff of a normal year as an example, the operation results of the hydropower plant operation model based on the DP and SDP algorithms were compared and analyzed to verify the rationality of the SDP. In order to show the water level process of the NZD hydropower plant under different incoming runoff in the current period after being dispersed, the corresponding water levels at the beginning and end of the month of the same representative flow were drawn on the same curve to obtain the yearly optimal operation water level diagram (Figure 11). 

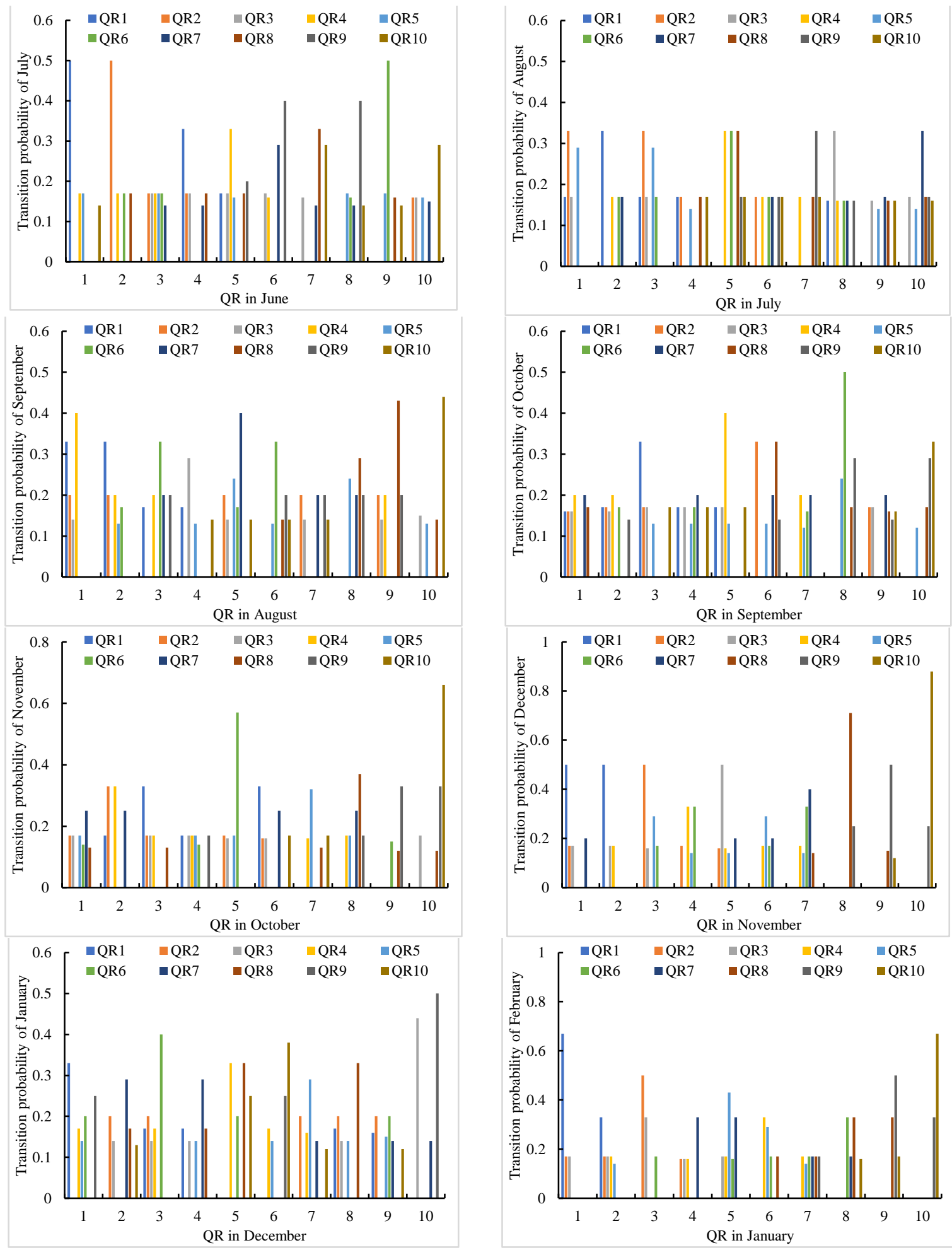

Figure 9. Cont. 

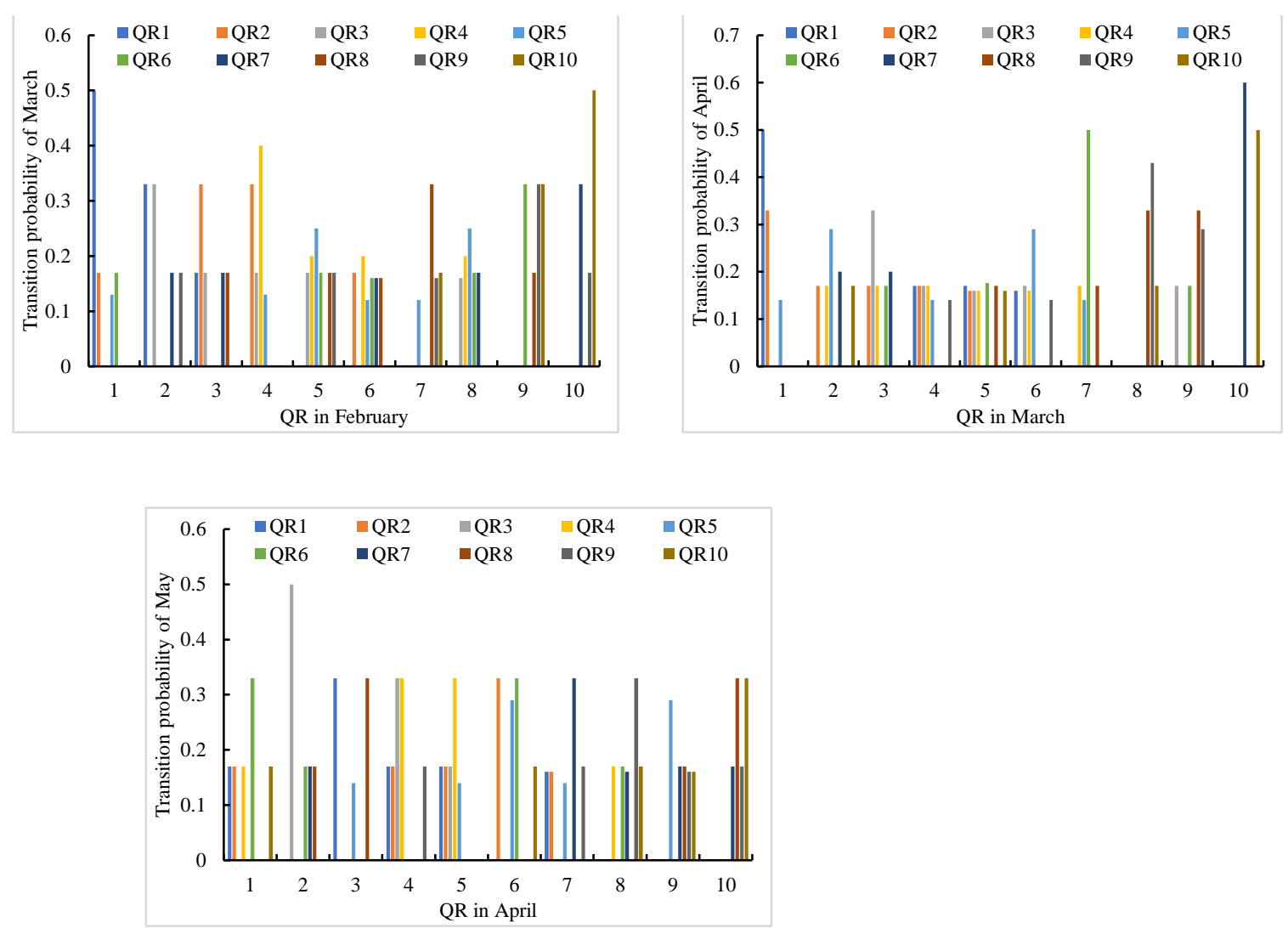

Figure 9. Transfer probability of the NZD hydropower plant for measured runoff.

Table 4. Representative flow in each month for simulated runoff of the NZD hydropower plant $\left(10^{8} \mathrm{~m}^{3}\right)$.

\begin{tabular}{ccccccccccc}
\hline & \multicolumn{1}{c}{ Month } & \multicolumn{1}{c}{ Representative Runoff QR } \\
\cline { 2 - 11 } & $\mathbf{1}$ & $\mathbf{2}$ & $\mathbf{3}$ & $\mathbf{4}$ & $\mathbf{5}$ & $\mathbf{6}$ & $\mathbf{7}$ & $\mathbf{8}$ & $\mathbf{9}$ \\
\hline June & 65.9 & 59.5 & 54.5 & 51.0 & 47.9 & 44.8 & 41.7 & 38.6 & 34.4 & 20.0 \\
July & 108.7 & 99.3 & 92.9 & 87.8 & 83.3 & 79.0 & 75.1 & 70.5 & 64.1 & 39.8 \\
August & 139.0 & 122.4 & 112.7 & 104.9 & 97.7 & 91.1 & 84.7 & 77.7 & 68.7 & 36.2 \\
September & 114.6 & 103.0 & 94.9 & 88.4 & 82.8 & 77.8 & 72.9 & 67.5 & 60.8 & 36.6 \\
October & 83.7 & 75.4 & 70.0 & 65.5 & 61.6 & 57.9 & 54.4 & 50.3 & 45.5 & 28.3 \\
November & 51.4 & 45.5 & 42.1 & 39.1 & 36.7 & 34.4 & 32.0 & 29.4 & 26.4 & 15.9 \\
December & 29.0 & 26.7 & 25.1 & 23.9 & 22.9 & 21.9 & 20.8 & 19.6 & 18.0 & 12.6 \\
January & 20.6 & 19.4 & 18.5 & 17.9 & 17.2 & 16.6 & 16.0 & 15.2 & 14.3 & 10.0 \\
February & 17.3 & 16.3 & 15.6 & 15.0 & 14.5 & 14.0 & 13.5 & 13.0 & 12.2 & 8.4 \\
March & 16.8 & 15.8 & 15.0 & 14.5 & 13.9 & 13.4 & 12.9 & 12.3 & 11.5 & 8.1 \\
April & 21.1 & 19.6 & 18.7 & 17.9 & 17.2 & 16.5 & 15.8 & 15.1 & 14.1 & 9.6 \\
May & 34.9 & 31.6 & 29.5 & 27.8 & 26.2 & 24.8 & 23.4 & 21.7 & 19.6 & 10.2 \\
\hline
\end{tabular}



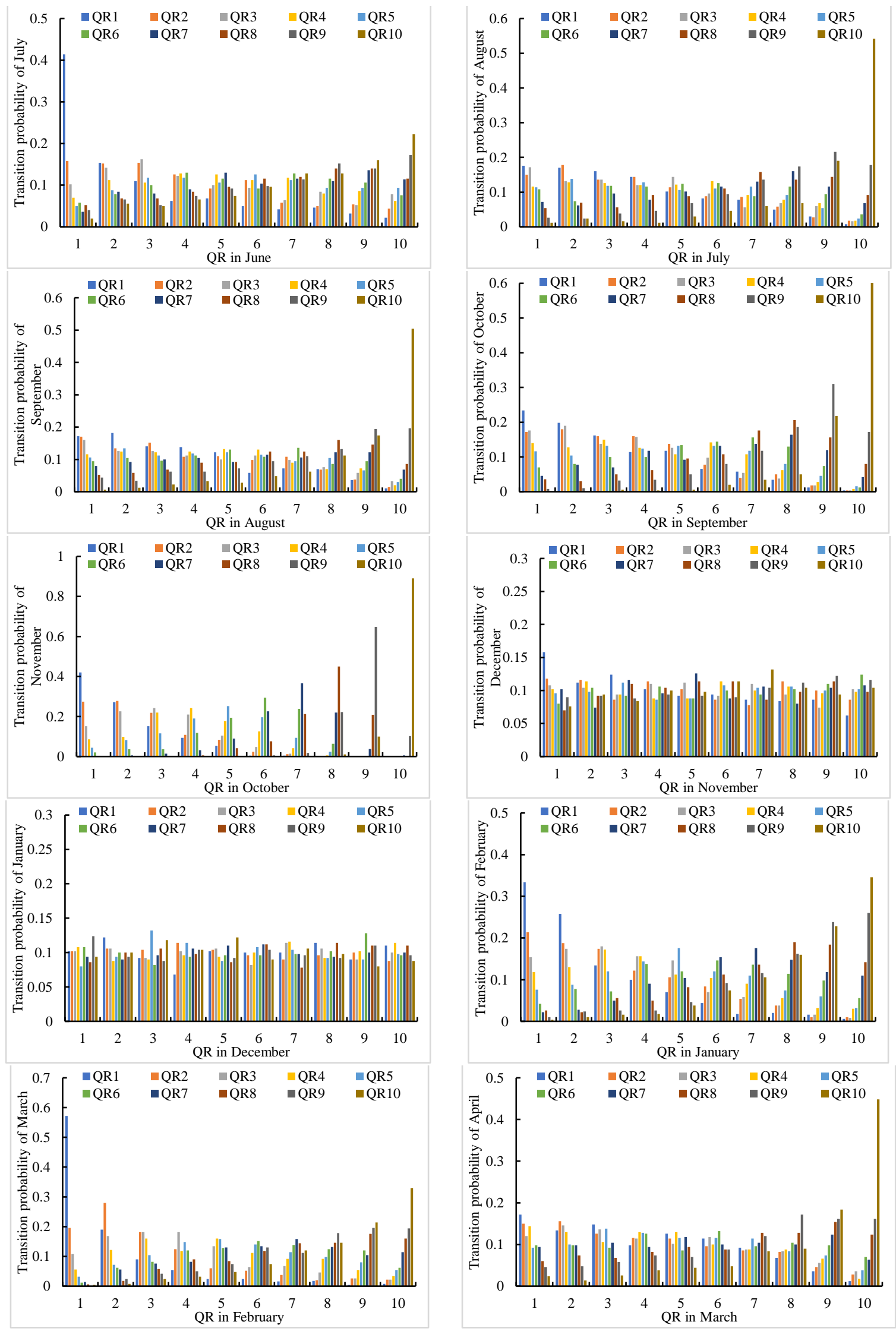

Figure 10. Cont. 


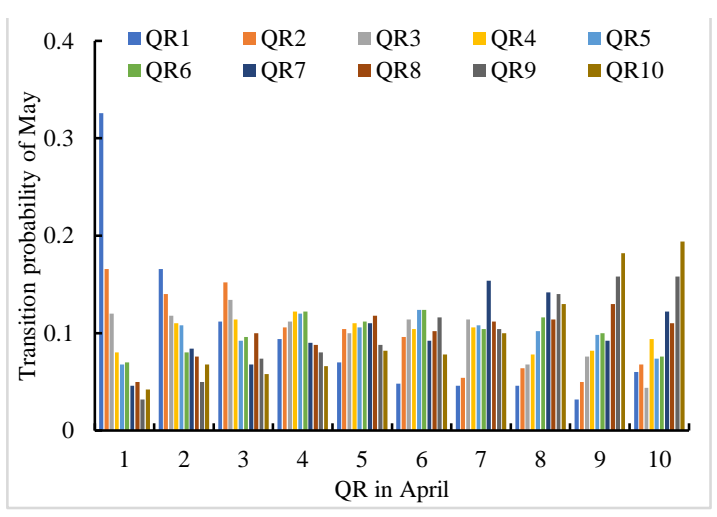

Figure 10. Transfer probability of the NZD hydropower plant for simulated runoff.

Taking the measured data as the input of the operation model, the optimal operation rules of power generation and the corresponding stage power generation expectation under the discrete water level and the incoming runoff at the beginning of each month were solved (Figure 11). Since the starting and ending period of annual operation of the NZD hydropower plant was from June to May of the next year, and the decision water level of May was fixed (dead water level), the operation rule was a vertical line. Similarly, in June of the next year, because the initial water level was fixed, the decision water level was a horizontal line. For other months, as the water level at the beginning of the month of the NZD hydropower plant increased, the increase trend of the water level at the end of the month was obvious; and as the range changed from QR1 to QR10, the corresponding water levels at the end of the month of the same water level at the beginning of the month showed an increase tendency, which proved the rationality of the water level operation diagram. The incoming runoff of the NZD hydropower plant in flood season (July to September) was large and unstable, so the curves of the July, August, and September operation diagrams were scattered and irregular. In the dry season, the curve of the corresponding water level in the operation diagram was denser, the curve space was closer and closer, and the curves even overlapped together, which was regular. The optimal operation diagram was used to obtain the corresponding end water level of a certain beginning water level by determining the representative range of any incoming runoff, which was convenient for operation in practice.

In order to examine the rationality of the operation rules formulated by the SDP, the deterministic dynamic programming (DP) was selected to obtain the operation results as a compared case. Taking the incoming runoff process of the NZD hydropower plant in a normal water year as an example, the SDP and DP algorithms were used to solve the operation model. The operation processes of the SDP and DP are shown in Figure 12. The annual power generation based on the SDP and DP were $305.97 \times 10^{8} \mathrm{~kW} \cdot \mathrm{h}$ and $306.91 \times 10^{8} \mathrm{~kW} \cdot \mathrm{h}$, respectively. The total power generation and operation process of the SDP was same as those of the DP, which proved to be reliable for the SDP. 

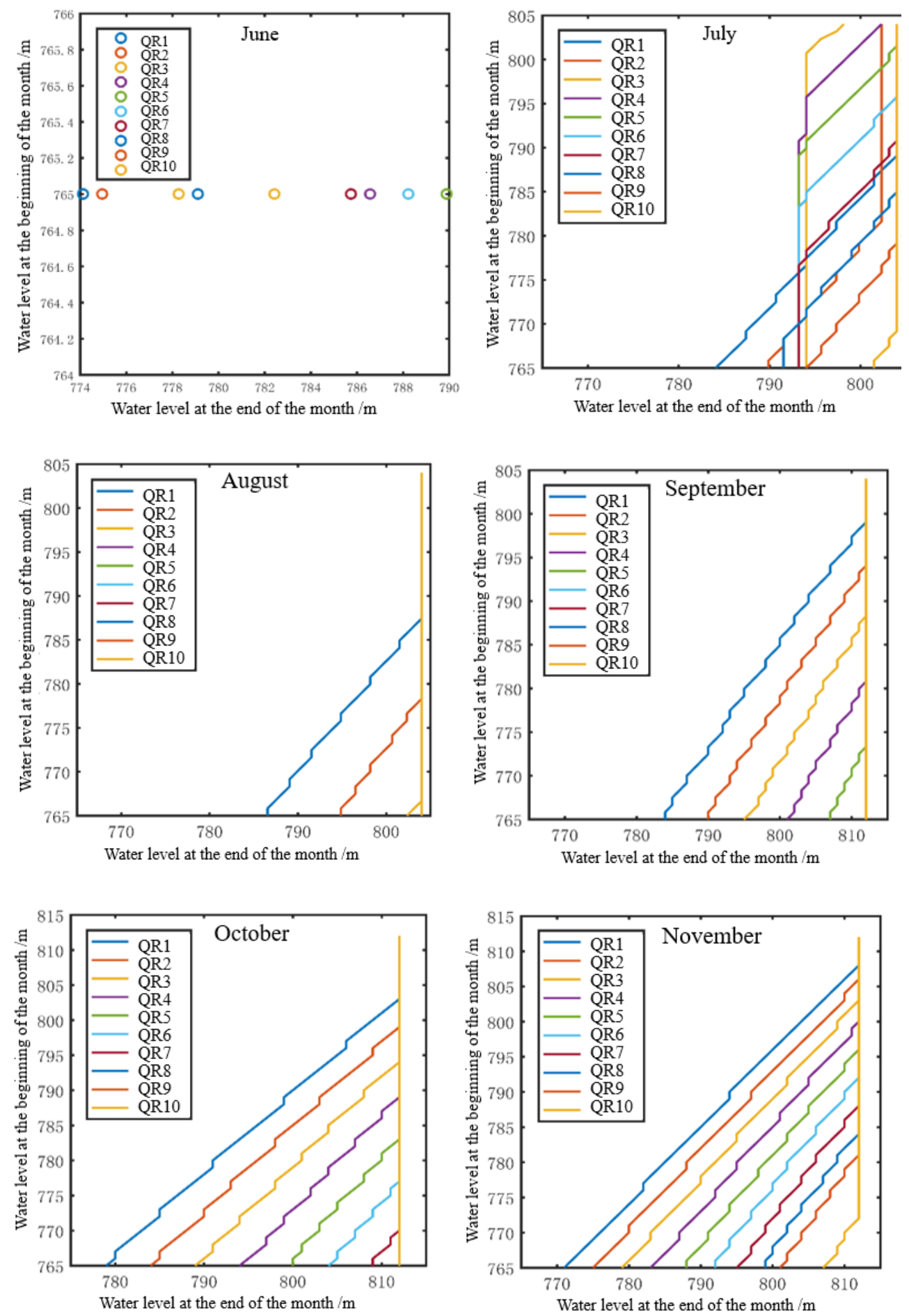

Figure 11. Cont. 

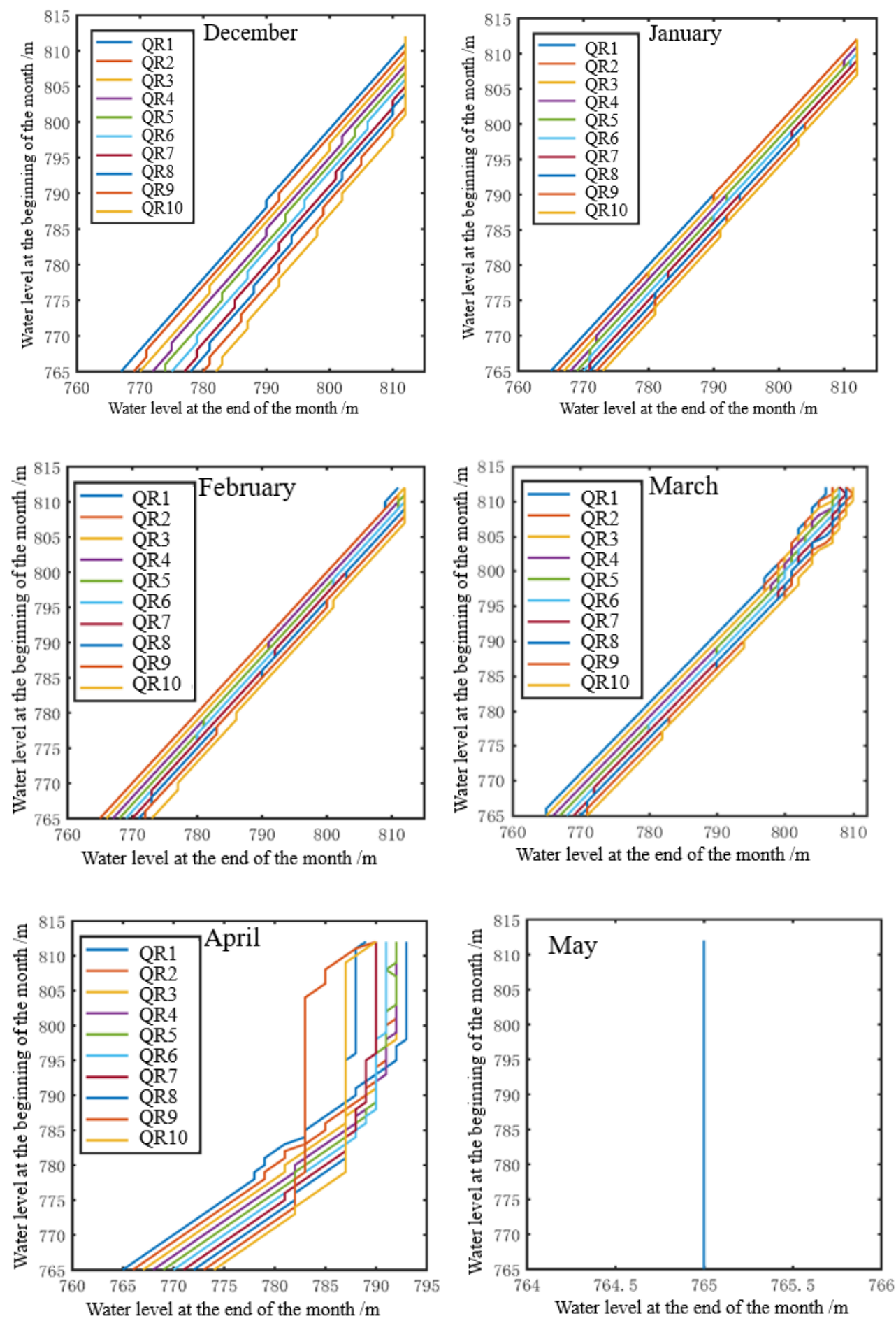

Figure 11. Results for operation of the NZD hydropower plant based on SDP. 


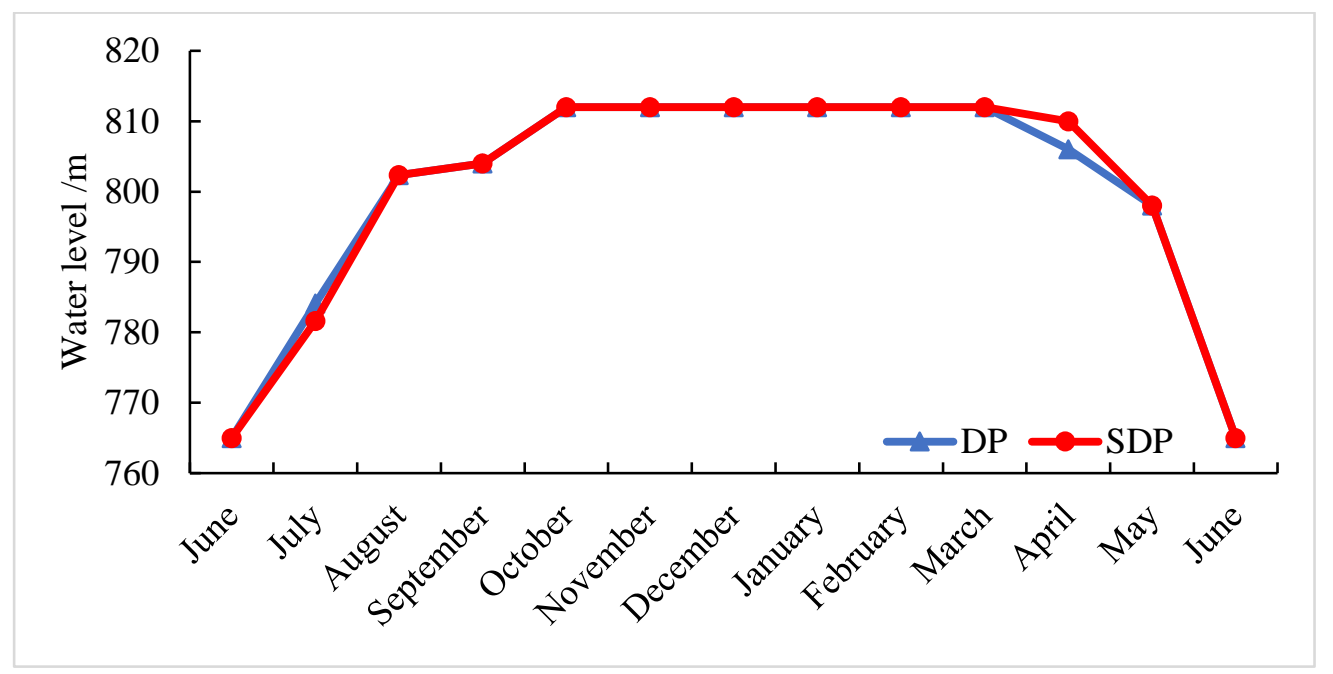

Figure 12. Results for operation of the NZD hydropower plant based on DP and SDP.

\section{Conclusions}

There are many uncertain factors faced during the actual operation of hydropower plants, among which the uncertainty of incoming runoff contributes the most. Therefore, taking into consideration the randomness of incoming runoff, more risk information about the actual operation of hydropower plants would be provided for decision-makers to make reasonable decisions. In this paper, the copula joint function was selected to construct the joint distribution of adjacent monthly runoff of the NZD hydropower plant, and the runoff simulation model was constructed based on the Gibbs method. While considering the randomness of incoming runoff, the stochastic optimal operation model was constructed and solved by the SDP algorithm.

The monthly incoming runoff of 5000 groups of the NZD hydropower plant were simulated based on the copula function and the Gibbs method. Setting the measured annual mean runoff as \pm 1 standard deviation as a reasonable range, the simulated runoff dropping into this range accounted for $71.12 \%$, and those exceeding this range accounted for $13.98 \%$ and lower than this range was $14.9 \%$, which showed the uncertainty of the incoming runoff.

The monthly runoff of the NZD hydropower plant was sorted, and 10 representative flows (frequency of $10 \% \sim 100 \%$ with range of $10 \%$ ) were selected. Due to the insufficiency of measured runoff, there were too many 0 values in the derived transfer probability, but after the simulated runoff series were introduced, the results significantly improved.

Taking the transfer probability matrix of simulated runoff as the input of the stochastic optimal operation model of cascade hydropower plants, the operation diagram containing the future-period incoming water information was obtained, which could directly provide a reference for the optimal operation of the Nuozhadu hydropower plant. In addition, taking the incoming runoff process in a normal year as the standard, the annual mean power generation based on stochastic dynamic programming was similar to that based on dynamic programming (respectively $305.97 \times 10^{8} \mathrm{~kW} \cdot \mathrm{h}$ and $306.91 \times 10^{8} \mathrm{~kW} \cdot \mathrm{h}$ ), which proved that the operation diagram constructed in this study was reasonable.

Author Contributions: J.C. came up with the idea and supervised the research; H.Z. and L.Z. did the simulation, validation, and finished the manuscript; Y.L. provided the methodology; R.L. modeling and calculating; Z.X. checked over the manuscript. All authors have read and agreed to the published version of the manuscript.

Funding: This research was supported by the National Natural Science Foundation of China (U2003204, U1965202, 52009053 and 51979038), and the National Key R\&D Program of China (2017YFC0406004).

Institutional Review Board Statement: Not applicable. 
Informed Consent Statement: Not applicable.

Conflicts of Interest: The authors declare no conflict of interest.

\section{References}

1. Chang, J.; Meng, X.; Wang, Z.; Wang, X.; Huang, Q. Optimized cascade reservoir operation considering ice flood control and power generation. J. Hydrol. 2014, 519, 1042-1051. [CrossRef]

2. Chang, J.; Guo, A.; Du, H.; Wang, Y. Floodwater utilization for cascade reservoirs based on dynamic control of seasonal flood control limit levels. Environ. Earth Sci. 2017, 76, 260. [CrossRef]

3. Zhang, L.; Huang, Q.; Liu, D.; Deng, M.; Zhang, H.; Pan, B.; Zhang, H. Long-term and mid-term ecological operation of cascade hydropower plants considering ecological water demands in arid region. J. Clean. Prod. 2021, 279, 123599. [CrossRef]

4. Wang, Y.M.; Chang, J.; Huang, Q. Simulation with RBF Neural Network Model for Reservoir Operation Rules. Water Resour. Manag. 2010, 24, 2597-2610. [CrossRef]

5. Ponnambalam, K.; Vannelli, A.; Unny, T.E. An application of Karmarkar's interior-point linear programming algorithm for multi-reservoir operations optimization. Stoch. Hydrol. Hydraul. 1989, 3, 17-29. [CrossRef]

6. Oliveira, R.; Loucks, D.P. Operating rules for multi-reservoir systems. Water Resour. Res. 1997, 33, 839-852. [CrossRef]

7. Chandramouli, V.; Raman, H. Multireservoir modeling with dynamic programming and neural networks. J. Water Resour. Plan. Manag. 2001, 127, 89-98.

8. Arunkumar, R.; Jothiprakash, V. Chaotic evolutionary algorithms for multi-reservoir optimization. Water Resour. Manag. 2013, 27, 5207-5222. [CrossRef]

9. Na, Y.; Ke, Z.; Yang, H.; Zhao, Q.; Huang, Q.; Xue, Y.; Xue, X.; Chen, S. Evaluation of the TRMM multisatellite precipitation analysis and its applicability in supporting reservoir operation and water resources management in Hanjiang basin, China. J. Hydrol. 2017, 549, 313-325.

10. Li, L.; Xu, H.; Chen, X.; Simonovic, S.P. Streamflow Forecast and Reservoir Operation Performance Assessment under Climate Change. Water Resour. Manag. 2010, 24, 83-104. [CrossRef]

11. Tegegne, G.; Kim, Y.O. Representing inflow uncertainty for the development of monthly reservoir operations using genetic algorithms. J. Hydrol. 2020, 586, 124876. [CrossRef]

12. Xu, B.; Huang, X.; Zhong, P.; Wu, Y. Two-phase risk hedging rules for informing conservation of flood resources in reservoir operation considering inflow forecast uncertainty. Water Resour. Manag. 2020, 34, 2731-2752. [CrossRef]

13. Galletti, A.; Avesani, D.; Bellin, A.; Majone, B. Detailed simulation of storage hydropower systems in large Alpine watersheds. J. Hydrol. 2021, 603 Pt D, 127125. [CrossRef]

14. Brekke, L.D.; Maurer, E.P.; Anderson, J.D.; Dettinger, M.D.; Townsley, E.S.; Harrison, A.; Pruitt, T. Assessing reservoir operations risk under climate change. Water Resour. Res. 2009, 45, 546-550. [CrossRef]

15. Celeste, A.B.; Billib, M. Evaluation of stochastic reservoir operation optimization models. Adv. Water Resour. 2009, 32, 1429-1443. [CrossRef]

16. Archibald, T.W.; Buchanan, C.S.; Mckinnon, K.; Thomas, L. Nested Benders decomposition and dynamic programming for reservoir optimisation. J. Oper. Res. Soc. 1999, 50, 468-479. [CrossRef]

17. Kumar, D.N.; Baliarsingh, F. Folded dynamic programming for optimal operation of multireservoir system. Water Resour. Manag. 2003, 17, 337-353. [CrossRef]

18. Ganji, A.; Khalili, D.; Karamouz, M.; Ponnambalam, K.; Javan, M. A Fuzzy Stochastic Dynamic Nash Game Analysis of Policies for Managing Water Allocation in a Reservoir System. Water Resour. Manag. 2008, 22, 51-66. [CrossRef]

19. Nikoo, M.R.; Kerachian, R.; Karimi, A.; Azadnia, A.A.; Jafarzadegan, K. Optimal water and waste load allocation in reservoir-river systems: A case study. Environ. Earth Sci. 2014, 71, 4127-4142. [CrossRef]

20. Yang, Z.; Wang, Y.; Yang, K. The stochastic short-term hydropower generation scheduling considering uncertainty in load output forecasts. Energy 2022, 241, 122838. [CrossRef]

21. Yang, Z.; Yan, K.; Wang, Y.; Su, L.; Hu, H. Multi-objective short-term hydropower generation operation for cascade reservoirs and stochastic decision making under multiple uncertainties. J. Clean. Prod. 2020, 276, 122995. [CrossRef]

22. Little, J.D.C. The Use of Storage Water in a Hydroelectric System. J. Oper. Res. Soc. Am. 1955, 3, 187-197. [CrossRef]

23. Howard, R.A. Dynamic Programming and Markov Processes. Math. Gaz. 1960, 3, 120.

24. Rossman, L.A. Reliability constrained dynamic programing and randomized release rules in reservoir management. Water Resour. Res. 1977, 13, 247-255. [CrossRef]

25. Bras, R.L.; Buchanan, R.; Curry, K.C. Real-time adaptive closed loop control of reservoirs with the High Aswan Dam as a case study. Water Resour. Res. 1983, 19, 33-52. [CrossRef]

26. Saadat, M.; Asghari, K. Feasibility Improved Stochastic Dynamic Programming for Optimization of Reservoir Operation. Water Resour. Manag. 2019, 33, 3485-3498. [CrossRef]

27. Shi, W.; Yu, X.; Liao, W.; Wang, Y. Spatial and temporal variability of daily precipitation concentration in the Lancang River basin, China. J. Hydrol. 2013, 495, 197-207. [CrossRef]

28. Zhang, H.; Chang, J.; Gao, C.; Wu, H.; Wang, Y.; Lei, K.; Long, R.; Zhang, L. Cascade hydropower plants operation considering comprehensive ecological water demands. Energy Convers. Manag. 2019, 180, 119-133. [CrossRef] 
29. Ogarekpe, N.M.; Tenebe, I.T.; Emenike, P.C.; Udodi, O.; Antigha, R.E.-E. Assessment of regional best-fit probability density function of annual maximum rainfall using CFSR precipitation data. J. Earth Syst. Sci. 2020, 129, 176. [CrossRef]

30. Hosseinifard, S.Z.; Abbasi, B.; Abdollahian, M. Performance Analysis in Non-Normal Linear Profiles Using Gamma Distribution. In Proceedings of the Eighth International Conference on Information Technology: New Generations, Las Vegas, NV, USA, 11-13 April 2011; IEEE: Piscataway, NJ, USA, 2011; pp. 603-607.

31. Papalexiou, S.M.; Koutsoyiannis, D. A global survey on the seasonal variation of the marginal distribution of daily precipitation. Adv. Water Resour. 2016, 94, 131-145.

32. Zhang, L.; Singh, V.P. Bivariate Rainfall and Runoff Analysis Using Entropy and Copula Theories. Entropy 2012, 14, 1784-1812. [CrossRef]

33. Qian, L.; Wang, X.; Wang, Z. Modeling the dependence pattern between two precipitation variables using a coupled copula. Environ. Earth Sci. 2020, 79, 1-12. [CrossRef]

34. Abdollahi, S.; Akhoond-Ali, A.M.; Mirabbasi, R.; Adamowski, J.F. Probabilistic Event Based Rainfall-Runoff Modeling Using Copula Functions. Water Resour. Manag. 2019, 33, 3799-3814. [CrossRef]

35. Mirabbasi, R.; Fakheri-Fard, A.; Dinpashoh, Y. Bivariate drought frequency analysis using the copula method. Theor. Appl. Climatol. 2012, 108, 191-206. [CrossRef]

36. Tao, S.; Sheng, D.; Wang, N.; Soares, C.G. Estimating storm surge intensity with Poisson bivariate maximum entropy distributions based on copulas. Nat. Hazards 2013, 68, 791-807. [CrossRef]

37. Valle, L.D.; Giuli, M.D.; Tarantola, C.; Manelli, C. Default Probability Estimation via Pair Copula Constructions. Eur. J. Oper. Res. 2016, 249, 298-311. [CrossRef]

38. Jackie, L. On the use of MCMC simulation for stochastic reserving. Aust. Actuar. J. 2008, 14, $227-271$.

39. Ma, H.; Zhu, G.; Zhang, Y.; Pan, H.; Guo, H.; Jia, W.; Zhou, J.; Yong, L.; Wan, Q. The effects of runoff on Hydrochemistry in the Qilian Mountains: A case study of Xiying River Basin. Environ. Earth Sci. 2019, 78, 1866-6280. [CrossRef]

40. Nandalal, K.; Sakthivadivel, R. Planning and management of a complex water resource system: Case of Samanalawewa and Udawalawe reservoirs in the Walawe river, Sri Lanka. Agric. Water Manag. 2002, 57, 207-221. [CrossRef]

41. Jha, D.K.; Yorino, N.; Zoka, Y.; Sasaki, Y.; Hayashi, Y.; Iwata, K.; Oe, R. Backward search approach to incorporate excess stream inflows in SDP based reservoir scheduling of hydropower plants. In Proceedings of the 2009 IEEE/PES Power Systems Conference $\mathcal{E}$ Exposition, Seattle, WA, USA, 15-18 March 2009; IEEE: Piscataway, NJ, USA, 2009.

42. Wu, X.; Cheng, C.; Lund, J.R.; Niu, W.; Miao, S. Stochastic dynamic programming for hydropower reservoir operations with multiple local optima. J. Hydrol. 2018, 564, 712-722. [CrossRef] 